\title{
Web Crippling Behaviour and Design of Cold-formed Steel Sections
}

\author{
B. Janarthanan, L. Sundararajah, M. Mahendran, P. Keerthan and S. Gunalan
}

Queensland University of Technology (QUT), Brisbane, QLD 4000, Australia

\begin{abstract}
Cold-formed steel sections are used in many different shapes based on their applications. Recently, a new C-section known as SupaCee was introduced in Australia with higher flexural capacities compared to traditional channel sections. However, all cold-formed steel sections are vulnerable to web crippling failures due to their higher plate slenderness. Australian/New Zealand (AS/NZS 4600) and North American (AISI S100) Standards use a unified web crippling design equation with four coefficients while Eurocode 3 Part 1.3 uses different design equations to predict the web crippling capacities of cold-formed steel sections. The web crippling coefficients were developed based on the experimental studies undertaken since the 1940s. These experimental studies utilised different test set-ups and specimens lengths and hence the accuracy of predictions using these coefficients may be inadequate. No coefficients are available for unlipped channel sections with fastened supports and high strength SupaCee sections while the same coefficeints are used for lipped channels with fastened and unfastened supports. To address these shortcomings, the web crippling behaviour of unlipped and lipped channel and SupaCee sections was experimentally investigated based on recently developed AISI S909 web crippling test guidelines. Finite element analyses were then performed to extend the range of cold-formed steel sections. Using the web crippling capacity results from both experiments and finite element analyses, new equations were proposed to determine the web crippling capacities of lipped and unlipped channel and SupaCee sections. Suitable direct strength method based web crippling design equations were also developed. This paper presents the important details of several detailed web crippling studies undertaken recently including a suite of web crippling design equations that can be adopted in relevant cold-formed steel standards.
\end{abstract}

Keywords: Cold-formed Steel Beams, Web Crippling, Lipped and Unlipped Channel Sections, SupaCee Sections, Experiments, Finite Element Analyses, ETF, ITF, EOF and IOF Load Cases, Design Rules, Direct Strength Method

*Corresponding author's email address: m.mahendran@qut.edu.au 


\section{Introduction}

Cold-formed steel unlipped and lipped channel sections are commonly employed as joists and bearers in floor systems due to their high flexural capacities. Recently, a new C-section known as SupaCee section was introduced in Australia, with enhanced flexural capacities compared with traditional unlipped and lipped channel sections (Fig. 1). These SupaCee sections are modified lipped channel sections with four longitudinal web stiffeners and curved lips. Although all cold-formed steel sections possess many advantages such as enhanced strength to weight ratios and dimensional accuracy, the main shortcoming is their vulnerablity to web crippling failure under transverse concentrated loads or support reactions as shown in Fig. 1, if the webs are unstiffened at the load transfer points. Theoretical development of suitable web crippling capacity equations has not been possible due to involved complexities such as nonuniform stress distribution and localised yielding and large deformations, inelastic behaviour of the web element and plate imperfections. Therefore the web crippling behaviour of many cold-formed steel profiles has been mainly investigated experimentally since the 1940s.

Current cold-formed steel standards such as North American Specification (AISI S100) [1], Australian/New Zealand standard (AS/NZS 4600) [2] and Eurocode 3 Part 1-3 [3] and AISI S909 web crippling test methods [4] classify web crippling failures into four groups (load cases): End-One-Flange (EOF), End-Two-Flange (ETF), Interior-One-Flange (IOF) and Interior-Two-Flange (ITF) based on the failure location and loading conditions as illustrated in Fig. 2. The load case is referred to as end loading for the failure within $1.5 d_{1}$ from the edge of the specimen. Otherwise, it is referred to as interior loading. Two-flange loading is the case when the distance between the edges of the bearing plates of opposite adjacent two loadings is less than $1.5 d_{1}$. Otherwise, it is one-flange loading, where $d_{1}$ is the height of the flat web portion.

Many series of experiments have been performed since the 1940s to investigate the web crippling behaviour of different shapes (C-, Z-, hat and built-up sections) of cold-formed steel sections [5-14]. Using all the available web crippling capacity data until 1994, Canadian researchers $[9,10]$ developed a unified equation to predict the web crippling capacity $\left(R_{b}\right)$ as shown in Eq. (1) based on web thickness $\left(t_{w}\right)$, yield strength $\left(f_{y}\right)$, web height to thickness ratio $\left(d_{1} / t_{w}\right)$, inside bent radius to thickness ratio $\left(r_{i} / t_{w}\right)$ and bearing length to thickness ratio $\left(l_{b} / t_{w}\right)$ with four coefficients $\left(C, C_{w}, C_{r}\right.$ and $\left.C_{l}\right)$. In Eq. (1), $\theta$ is the the inclination angle of web with the bearing surface. Cold-formed steel sections were classified into three groups such as single- 
web, multi-web and I-sections and suitable values were given for the above coefficients under all four load cases $[9,10]$. However, the proposed coefficients are limited to thin cold-formed steel sections with their thickness less than $1.9 \mathrm{~mm}$ for single-web sections, $3.8 \mathrm{~mm}$ for Isections and $1.7 \mathrm{~mm}$ for multi-web sections while the material yield strength was limited between 208 and $396 \mathrm{MPa}$. The unified web crippling capacity equation was accepted in AISI S100 [1] and AS/NZS 4600 [2] standards and the coefficents were later updated based on [11]. Due to the advancements in cold-forming technology, sections with thickness up to $7 \mathrm{~mm}$, made of steels with measured yield strengths of up to $700 \mathrm{MPa}$ are currently available in the industry. Since the current design equation was developed mostly using the data of thin sections, its accuracy for thicker cold-formed steel sections and sections made of higher strength steel is unknown. On the other hand, Eurocode 3 Part 1-3 [3] uses different and more complicated equations for each load case (EOF, IOF, ETF and ITF).

$$
R_{b}=C t_{w}^{2} f_{y} \sin \theta\left(1-C_{w} \sqrt{\frac{d_{1}}{t_{w}}}\right)\left(1-C_{r} \sqrt{\frac{r_{i}}{t_{w}}}\right)\left(1+C_{l} \sqrt{\frac{l_{b}}{t_{w}}}\right)
$$

Bhakta et al. [6] first reported the web crippling capacity enhancement due to fastened supports of different cold-formed steel sections compared to unfastened supports. As seen in Figs. 1(c) and 1(d), the web crippling failure modes depend on the type of support (unfastened or fastened). Cain et al. [7] examined the effects of fastening flanges to supports on the web crippling capacities of Z-sections and 12 I-sections. The web crippling capacity was 32 to 55\% higher for Z-Sections when their flanges were fastened. Gerges and Schuster [8] investigated the web crippling capacities of lipped channel sections with fastened supports and large bent radius. These research studies [6-8] proved that web crippling capacity is enhanced by fastened supports and the effect of fastened support was incorporated within AS/NZS 4600 [2] and AISI S100 [3] for some cold-formed sections. However, Eurocode 3 Part 1-3 [3] provides the same equations for both fastened and unfastened supports.

As shown in Fig. 3, past studies have used different test set-ups for one-flange load cases such as two mono-symmetric sections connected as a box-beam [5,8], two sections connected back to back [12] and only one section [13,14]. Compared to Hetrakul and Yu's [5] test set-up, Gerges and Schuster [8] used wooden blocks between the top and bottom flanges to prevent flange curling. However, this may transfer part of the applied load from the section's top flange to its bottom flange. The load is directly transferred via the web of the sections in a back to 
back test set-up while it is transferred to the web via flange in a box beam test set-up. Single specimens used in $[13,14]$ are not torsionally stable. Hence the use of such different test arrangements might have led to inaccurate web crippling capacities.

Beshara and Schuster [11] reported that web crippling capacity was not only affected by support conditions but also by specimen lengths. They observed up to $50 \%$ higher web crippling capacities for two-flange load cases for longer specimens. However, different specimen lengths were used in the past experimental studies under two-flange load cases [5,1114]. The specimen length varied from $1.5 d+l_{b}[5,12], 400$ and $600 \mathrm{~mm}[13,14]$ and $3 d$ and $5 d$ for ETF and ITF load cases [11], where $d$ is the overall section depth and $l_{b}$ is the bearing length. Such use of different specimen lengths might have led to inaccurate capacities.

Since the differences in the test arrangements including support conditions and loading method, and specimen lengths [6-14] might have produced inaccurate web crippling capacities, the currently available AISI S100 [1], AS/NZS 4600 [2] and Eurocode 3 Part 1-3 [3] design equations should be recalibrated. The current design equation also has other shortcomings such as (1) no coefficients for unlipped channel sections if their flanges are fastened to supports under one-flange load cases, (2) same coefficients for lipped channel sections under one-flange load cases with unfastened and fastened supports and (3) no coefficients for the new sections such as SupaCee sections (4) limited to geometrical and mechanical properties of the tested sections, for example, $r_{i} / t_{w}<3 ; d_{1} / t_{w}<200$ (5) predictions are unsafe even for conventional sections in some cases $[13,14]$. Their accuracy should also be checked for high strength steel sections.

To address the shortcomings in the past test set-ups and specimen lengths, AISI S909 [4] standard web crippling test methods were developed recently. It suggests the use of two monosymmetric sections in a box-beam arrangement and connect each other at one-fourth points of the specimen length at the top and bottom flanges for one-flange load cases while single sections can be used for two-flange load cases. It also recommends minimum specimen lengths ( $\left.L_{\min }\right)$ in terms of $d_{1}$, the flat web depth (Eqs. (2a to $\left.2 \mathrm{~d}\right)$ ).

End-One-Flange loading: $L_{\min }=3 d_{1}+3 \times$ bearing length

Interior-One-Flange loading: $L_{\min }=3 d_{1}+3 \times$ bearing length

End-Two-Flange loading: $L_{\min }=3 d_{1}$

Interior-Two-Flange loading: $L_{\min }=5 d_{1}$ 
Using the recently developed AISI S909 standard web crippling test methods [4], a group of researchers from Queensland University of Technology investigated the web crippling behaviour of thin-lipped and unlipped channel sections with unfastened supports under all four load cases [15-21], thick unlipped channels sections with unfastened supports (Duragal sections) under all four load cases [22,23], and unlipped channel sections with fastened supports under one-flange load cases [24,25]. In addition, Sundararajah et al. $[17,18]$ also investigated the behaviour of SupaCee sections with unfastened supports under all four web crippling load cases. They also investigated the web crippling behaviour using finite element analyses and expanded the web crippling capacity data base for cold-formed steel sections beyond those tested and to most commercially available sections. Their research addressed the shortcomings of the current web crippling design equations [1-3] discussed earlier through more than 300 web crippling tests and 1500 numerical analyses. This paper summarizes the details of their experimental and numerical studies including the important outcomes, and provides the improved web crippling capacity equations developed by them.

\section{Experimental studies}

\subsection{Test specimens and set-up}

Table 1 summarises the details of the experimental investigations into the web crippling behaviour of cold-formed steel unlipped channel, lipped channel and SupaCee sections with unfastened and fastened supports under all four load cases. It provides the considered ranges of important section dimensions for web crippling, namely, overall depth, thickness and inside corner radius of cold-formed steel sections and the number of tests performed under each load case. Sundararajah et al. [15-20] and Sundararajah [21] researched the web crippling behaviour of lipped, unlipped and SupaCee sections with their overall depth varying from 100 to $250 \mathrm{~mm}$ and thickness from 1.0 to $2.4 \mathrm{~mm}$. Their sections were made of high strength steels with nominal yield strengths of 450, 500 and $550 \mathrm{MPa}$. However, the measured yield strengths varied between 506 to $581 \mathrm{MPa}$ for lipped channel sections, 510 to $624 \mathrm{MPa}$ for SupaCee sections and 535 to $591 \mathrm{MPa}$ for unlipped channel sections. Gunalan and Mahendran [22,23] investigated the web crippling behaviour of thick unlipped channel sections under all four load cases with their depth in the range of 75 to $300 \mathrm{~mm}$, thickness between 3.8 and $6.0 \mathrm{~mm}$ and inside corner radius between 4.0 and $8.0 \mathrm{~mm}$. Janarthanan et al. [24] examined the web crippling behaviour of thick unlipped channel sections, which had similar dimensions as 
Gunalan and Mahendran's [22] test specimens. In addition, Janarthanan et al. [24] also included thin sections with their overall depth in the range of 150 to $200 \mathrm{~mm}$ and thickness in the range of 1.5 to $2.4 \mathrm{~mm}$. The specimens used by Gunalan and Mahendran [22,23] and Janarthanan et al. [24] are made of steel with a nominal yield strength of $450 \mathrm{MPa}$. However, the measured yield strengths varied between 449 and $483 \mathrm{MPa}$ in [22,23] and between 457 and $534 \mathrm{MPa}$ in [24]. In all these experimental studies, the cross-sectional dimensions of test specimens and their lengths were measured and recorded before conducting each test. The stress-strain characteristics of all cold-formed steel sections were obtained by performing tensile coupon tests, and the important mechanical properties of yield strength, ultimate strength and elasticity modulus were determined. Four bearing lengths of 25, 50, 100 and $150 \mathrm{~mm}$ were used in Gunalan and Mahendran's [22] two-flange load case while 25, 50 and 100 mm bearing lengths were used for all four load cases of lipped channel sections investigated by Sundararajah et al. $[15,16]$. In all other web crippling investigations, 50, 100 and $150 \mathrm{~mm}$ bearing lengths were used.

AISI S909 [4] standard web crippling test method was strictly followed in terms of the specimen length and test arrangement in the above-mentioned research studies [15-25]. Since unlipped and lipped channel and SupaCee sections are mono-symmetric, two similar sections were placed in a box-beam arrangement, connected to each other using small steel angles at quarter points at the top and bottom flanges to provide a torsionally stable arrangement for oneflange load cases as illustrated by Fig. 4. For two-flange load cases, a single section was placed on the supports as shown in Fig. 5 . Specimen lengths were taken as $3 d+3 l_{b}$ for one-flange load cases, $3 d$ for end-two-flange load case and $5 d$ for interior two-flange load case, where $d$ is the overall section depth and $l_{b}$ is the bearing length, which satisfy the minimum specimen length requirements of AISI standard web crippling test method [4]. Test specimens were simply placed on hinge supports developed using bearing plates and half rounds. For EOF load case, the web element was stiffened on both sides at the mid-span of the specimen using $20 \mathrm{~mm}$ thick steel plates whereas the web elements at the end supports of the specimen were stiffened for IOF load case (Fig. 4). The load was applied by an Instron testing machine using displacement control method until web crippling failure occurred, during which period, the vertical and lateral deflections were recorded at web crippling locations. The load versus vertical deflection at mid-point and the load versus out-of-plane web deflection curves were plotted for each test and used for finite element validation purposes (shown in later sections). 


\subsection{Test results}

The web crippling capacities $\left(R_{b}\right)$ of the tested sections were calculated using the web crippling design equations of AS/NZS 4600 [2] and Eurocode 3 Part 1-3 [3] using the measured section dimensions and material yield strengths. It should be noted that AS/NZS 4600 and AISI S100 web crippling equations are identical. The code-predicted web crippling capacities were then compared with experimental web crippling capacities and the resulting mean values and COVs of the ratios of predicted and experimental capacities are given in Table 2. Table 2 shows that Eurocode 3 Part 1-3 [3] predicted the web crippling capacities of thin lipped and unlipped channel and SupaCee sections under two-flange load cases accurately, but underestimated the web crippling capacities of the same sections for one-flange loading with unfastened supports. However, the web crippling predictions using Eurocode 3 Part 1-3 [3] for unlipped thick channel sections (Duragal sections) were unsafe for ETF, ITF and IOF load cases with unfastened supports. Since Eurocode 3 Part 1-3 [3] does not differentiate between fastened and unfastened supports, it underestimated the EOF web crippling capacities of unlipped sections fastened to their supports by $100 \%$, while agreeing well for IOF load cases.

In all comparisons shown in Table 2, AS/NZS 4600 [2] unified web crippling design equation (Eq.1) with suitable values of coefficients $C, C_{w}, C_{r}$ and $C_{l}$ accurately predicted the web crippling capacities of thin-lipped channel sections under one-flange load cases and SupaCee sections under IOF load case with unfastened supports. However, its predictions for all other cold-formed steel sections were inconsistent, conservative for some load cases and unconservative for other load cases. Also, AS/NZS 4600 [2] does not provide any coefficients for unlipped channel sections fastened to supports. Therefore, the experimental web crippling capacities were compared with the predictions using unlipped channel sections unfastened to supports (EOF-1 \& IOF-1) and lipped channel sections fastened to supports (EOF-2 \& IOF-2). Again these coefficients predicted the web crippling capacities of unlipped channel sections with fastened supports under one-flange loading inconsistently. No web crippling coefficients are available for SupaCee sections in AS/NZS 4600. Therefore, SupaCee sections were considered as lipped channel sections and their web crippling capacities were predicted. Again, the capacity comparisons showed that predictions for SupaCee sections using AS/NZS 4600 web crippling coefficients are inconsistent. This shows the need for new values for the four web crippling coefficients, $C, C_{w}, C_{r}$ and $C_{l}$. 
New web crippling coefficients were proposed using the results of all the web crippling experimental studies [15-25] and are listed in Table 3. The mean and COV values in Table 3 confirm the accuracy of the new coefficients. Suitable capacity reduction factors $\left(\phi_{w}\right)$ were also proposed using the recommended procedure given in AISI S100 [1] and a reliability index of 2.5. However, the application of the new coefficients based on the experimental study is limited to only those sections tested. Comparison of Janarthanan et al.'s [24] and Gunalan and Mahendran's [22] test results revealed that the web crippling capacity of thick unlipped channels was increased by 32.8\% for EOF loading and 8\% for IOF loading. This also proved that web crippling capacities were greatly influenced by support conditions and justified the need for new coefficients.

\section{Finite element analysis}

\subsection{Development and validation of finite element models}

The applicability of the proposed coefficients in Table 3 for use with the unified web crippling capacity equation (Eq.1) is in general limited to cold-formed steel sections with similar geometry and material characteristics. To expand their applicability further, Sundararajah et al. [17-20] and Janarthanan [25] developed suitable web crippling finite element models using ABAQUS/CAE Version 6-14 [26] and validated them using their experimental data.

The first web crippling FE models were developed by Sivakumaran [27] for lipped channels using ADINA software under IOF loading. Ren et al. [28] extended Young and Hancock's [12] web crippling study of unfastened unlipped channels under one-flange loading using ANSYS. Macdonald et al. [13] and Macdonald and Heiyanthutuwa [14] also extended their studies on unfastened lipped channels using ANSYS. All of these FE studies were performed based on non-linear static analysis. However, Kaitila [29] first discussed the convergence difficulties with nonlinear static analysis when web crippling FE models were used with contacts and used ABAQUS/Explicit analysis instead. Natario et al. [30,31] also recommended the use of quasistatic analysis with ABAQUS/Explicit and suggested solution enhancement techniques such as mass scaling and artificial loading rate. The above studies showed that accurate results can be obtained if validated FE models are developed and used. Researchers from QUT also developed FE models, validated them as explained in [17-21,25] and extended the outcomes of their experimental studies. 
Since the thickness of cold-formed steel sections is small compared to other dimensions, their FE models were developed using 3-D shell elements. The accuracy of FE models depends on the element and mesh types. Deformable shell elements are classified into S4, S4R, S4RS and S4RSW for ABAQUS/Explicit analysis, where the first three element types were able to give the web crippling capacities accurately than S4RSW element. Also, S4 element required more computational time and generated a larger output file compared to S4R element. Therefore S4R element was employed in the FE models in [17-21, 25]. Mesh size is critical in FE modelling as using a coarse mesh reduces the accuracy while a fine mesh increases the computational time and resources. Hence $5 \mathrm{~mm} \times 5 \mathrm{~mm}$ mesh was used for both web and flange elements with a finer mesh of $5 \mathrm{~mm} \times 0.5 \mathrm{~mm}$ at their corner regions to enable proper flange to web load transfer and to accurately model the significant effects of corner radius associated with plastic deformations at the web-flange juncture. Four noded rigid elements R3D4 of $10 \mathrm{~mm}$ x $10 \mathrm{~mm}$ were used to model loading and support bearing and web side plates. In some cases, the web side plates were simulated by increasing the web thickness at corresponding locations. The measured mechanical properties can be input to ABAQUS software using bilinear or multilinear material models with strain-hardening effects. However, since the strain hardening effect on the web crippling capacity was found to be small, bilinear material model was used in all the parametric studies.

Single cold-formed section was simulated in FE modelling with appropriate boundary conditions. All the boundary conditions were assigned to the reference points of support and loading plates and then transferred to flanges of steel sections using contacts only. In contacts, loading and support plates were assigned as master surface and steel sections were assigned as slave surface. The surface-to-surface technique was used to generate contact between the loading plate and steel sections and hard contact was employed. Based on pressure-over closure behaviour, contacts are grouped into hard contact and soft contact. The contact stiffness value is infinity for hard contact while different contact stiffness values can be used for soft contact. The use of hard contact and soft contact with higher contact stiffness value of $10000 \mathrm{kN} / \mathrm{m}^{3}$ predicted almost the same web crippling capacities [17-21,25]. However, using soft contacts reduces convergence issues. Sundararajah et al. [17-20] used hard contacts in their FE models while Janarthanan [25] used soft contacts with contact stiffness value of $10000 \mathrm{kN} / \mathrm{m}^{3}$.

Boundary conditions for ETF load case are similar to ITF load case, but the location of loading and support plates are at the end and mid-span of the specimen for ETF and ITF load cases, 
respectively. Fig. 6 shows the used boundary conditions for lipped channel sections under ITF loading. As shown in Fig. 6, translations in all three directions and rotation about the longitudinal axis (z-axis) were fixed at the support plates while translations in $\mathrm{x}$ and $\mathrm{z}$-axes and rotation about z-axis were fixed at the loading plate. A vertical displacement of $20 \mathrm{~mm}$ was assigned in the y-axis and the displacement rate was controlled using a smooth step function. The boundary conditions of channel sections for EOF loading are shown in Fig. 7 and are similar to the IOF loading. The difference between EOF and IOF FE models is the location of failure and web side plates. The web side plates were simulated at the specimen ends for IOF loading and at the mid-span for EOF loading (Fig. 7). For flange-fastened unlipped channels, $12 \mathrm{~mm}$ diameter hole was created in their bottom flange at the corresponding M12 bolt location and the hole perimeter was connected to the reference point of the support plates using MPC rigid tie constraint as shown in Fig. 8.

Quasi-static analysis based on an explicit scheme in ABAQUS/CAE was employed to avoid the convergence issues caused by contact and material complexities in the static and quasistatic analysis based on implicit scheme. Quasi-static analysis method was considered the most suitable approach by other researchers [29-31] and was used here for all the sections and load cases $[17-21,25]$. The loading process used in the web crippling tests in which the loading plate is moved at a constant displacement rate is simulated well by quasi-static analysis. Quasi-static analysis based on the explicit scheme is performed based on stable time increment, which depends on the characteristic length and wave propagation velocity. The propagation velocity depends on Young's modulus and density of the material and for steel, the value is $5000 \mathrm{~ms}^{-1}$. The characteristic length is defined as the smallest mesh size used in the FE model and is equal to $0.5 \mathrm{~mm}$. For steel sections, stable time is $1 \times 10^{-7}$ and analysis time is 1200 seconds if the small mesh size is $0.5 \mathrm{~mm}$ and vertical displacement is $20 \mathrm{~mm}$. Although this analysis is stable, it requires more time to complete the analysis. Therefore computational efficiency of the analysis can be enhanced by using mass scaling and artificial loading rate. Kinetic energy and inertial effects are increased with the use of mass scaling and artificial loading rate. The inertial effect is high for thin members compared to thick sections with increasing mass scaling. Therefore, Sundararajah et al. [17-20] did not use mass scaling or artificial loading rates due to thin sections while Janarthanan [25] used mass scaling of 10 in their models.

The developed FE models were analysed and the results of web crippling failure load, failure mode and load versus deflection curves were compared with corresponding experimental test 
data for validation purposes. It was found that the FE models accurately represented the web crippling behaviour and capacity of unlipped channel sections with fastened supports under one-flange load cases, lipped channel and SupaCee sections under all load cases. Figs. 9 and 10 show selected comparisons of failure modes from FE analyses and experiments. Other comparisons and full details of FE modelling are available in the detailed papers and theses mentioned above [17-21,25].

\subsection{Parametric studies}

Sundararajah et al. [17-20], Sundararajah [21] and Janarthanan [25] conducted detailed parametric studies using the validated FE models for lipped channel sections under all four load cases and unlipped channel sections with fastened supports under one-flange load cases, respectively. The objectives of their parametric studies were to (1) investigate the web crippling behaviour of the above-mentioned cold-formed steel sections further (2) create a large web crippling capacity database covering a wider range of section geometry and material specifications and then (3) to develop new and/or improved design equations for inclusion in cold-formed steel standards. Details of these parametric studies are summarized in Table 4. Sundararajah et al. [17-20] considered six commercially available lipped channel sections with varying depths, thicknesses, inside corner radii and yield strengths while Janarthanan [25] considered 12 commercially available unlipped channel sections with similarly varying parameters. In both parametric studies, bearing plate lengths of 50, 100 and $150 \mathrm{~mm}$ were used. The effects of different parameters such as inside bent radius to thickness ratio, bearing length, web slenderness ratio and the material yield strength on the web crippling capacity were investigated using more than 1500 web crippling capacity data.

Both experimental and FE studies [17,18] showed that the presence of longitudinal web stiffeners in SupaCee sections caused localized failures and high stresses along the web stiffeners for ITF, EOF and IOF load case, leading to reductions in the web crippling capacities by up to about $19 \%$ in comparison with similar sized lipped channels, an unexpected result. 


\section{Proposed web crippling design equations}

\subsection{AS/NZS 4600 and AISI S100 design equation}

Based on the detailed parametric studies, Sundararajah et al. [15-20] provided accurate values for the web crippling coefficients $C, C_{w}, C_{r}$ and $C_{l}$ for use with the unified web crippling design equation in AS/NZS 4600 and AISI S100 (Eq.(1)) to predict the web crippling capacities of lipped channel sections with unfastened supports under all four load cases. Similarly, Janarthanan [25] improved the web crippling coefficients for unlipped channel sections whose flanges are fastened supports. Table 5 lists the web crippling coefficients proposed by them based on parametric study results. For other sections and support conditions, the coefficients based on experimental or both experimental and corresponding FE analysis results are given [21-23].

Sundararajah et al. [15-20] observed that the COVs for their web crippling capacity predictions of lipped channels under the four load cases were high (0.15 to 0.20$)$. They attributed this to the effect of varying material yield strength. Hence they proposed a material yield strength factor as shown in Eq. (3) and included it in Eq. (1). Eq. (4) shows the modified AS/NZS 4600 design equation with the new factor. Suitable values for the five coefficients in the new equation are shown in Table 6.

Material yield strength factor $=1+C_{s} \sqrt{\frac{250}{f_{y}}}$

where: $C_{\mathrm{s}}=$ Web yield stress coefficient

$$
R_{b}=C t^{2} \sin \theta f_{y}\left(1+C_{s} \sqrt{\frac{250}{f_{y}}}\right)\left(1-C_{w} \sqrt{\frac{d_{1}}{t}}\right)\left(1-C_{r} \sqrt{\frac{r_{i}}{t}}\right)\left(1+C_{l} \sqrt{\frac{l_{b}}{t}}\right)
$$

Janarthanan [25] also found that the web crippling capacity variation is not proportional to the material yield strength as implied by Eq. (1). He also proposed a material yield strength factor as shown in Eq. (5) for fastened unlipped channels, which is different to Eq.3. Eq. 6 shows the modified AS/NZS 4600 design equation with the material yield strength factor. Janarthanan [25] proposed coefficients for the new equation as listed in Table 6 to calaculate the web crippling capacities of unlipped channel sections with fastened supports accurately.

Material yield strength factor $=1+C_{s} \frac{250}{f_{y}}$ 


$$
R_{b}=C t^{2} \sin \theta f_{y}\left(1+C_{s} \frac{250}{f_{y}}\right)\left(1-C_{w} \sqrt{\frac{d_{1}}{t}}\right)\left(1-C_{r} \sqrt{\frac{r_{i}}{t_{w}}}\right)\left(1+C_{l} \sqrt{\frac{l_{b}}{t_{w}}}\right)
$$

\subsection{Direct Strength Method (DSM)}

Direct Strength Method (DSM) provides an alternative approach to the effective width method in predicting the capacities of cold-formed steel sections. Both AISI S100 [1] and AS/NZS 4600 [2] have adopted DSM for cold-formed steel members under axial compressive, flexural (global, distortional and local buckling) and shear loads. However, they do not yet have any DSM guidelines for web crippling capacities. A DSM-based web crippling design can be superior to the empirical method of using a unified equation developed based on the four most influential web crippling parameters (Eqs. (4) and (6)).

In the past, several researchers [32-37] have proposed DSM-based web crippling design equations for cold-formed steel sections under different load conditions using a format of Eq. (7), which depends on two key parameters, the critical buckling load $\left(R_{b, c r}\right)$ and the yield load $\left(R_{b, y}\right)$.

$$
R_{b}=n_{3} R_{b, y}\left[1-n_{1}\left(\frac{R_{b, c r}}{R_{b, y}}\right)^{n_{2}}\right]\left(\frac{R_{b, c r}}{R_{b, y}}\right)^{n_{2}}
$$

Sundararajah et al. [15-20] and Sundararajah [21] proposed DSM based equations for unlipped and lipped channel and SupaCee sections with unfastened support conditions for all four load cases. They determined the buckling loads using elastic buckling FE analyses and the yield loads using idealised failure mechanisms derived based on the failure modes observed in experiments and finite element simulations. However, finite element analysis is too complicated for the everyday usage in engineering practice. Therefore, suitable equations were proposed to predict the buckling load $\left(R_{b, c r}\right)$ and yield load $\left(R_{b, y}\right)$ of cold-formed steel sections based on their finite element analysis results.

\section{Critical Buckling Load ( $\left.\mathbf{R}_{\mathbf{b}, \mathrm{cr}}\right)$}

The critical buckling loads of unlipped and lipped channels and SupaCee sections with unfastened supports for all four load cases were obtained from linear elastic buckling analyses of simplified FE models in ABAQUS/CAE. The load applied through the bearing plate was 
simulated by nodal forces at the web-flange junction while appropriate boundary conditions were used to simulate the sections under different loading conditions as shown in Figure 11. Further details are given in [15-21]. The FEA buckling loads were then converted to buckling coefficients ( $k$ ) using Eq. (8).

$$
R_{b, c r}=\frac{\pi^{2} E k t_{w}^{3}}{12\left(1-v^{2}\right) d_{1}}
$$

where $k$ - critical buckling coefficient, $t_{w}$ - the section/web thickness, $d_{1}$ - clear height of the web, $E$ - Young modulus of steel (200,000 MPa), v - Poisson's ratio

Based on the obtained critical buckling load data, a suitable equation was proposed with five different coefficients linking the four important parameters in the form of Eq. (9) to calculate the critical buckling loads in a similar manner to that of web crippling capacity (Eq. (1)). Table 7 gives the proposed values for these five coefficients. This eliminates the need to undertake buckling analyses.

$$
k=C_{b}\left(1-C_{b, r} \sqrt{\frac{r_{i}}{t_{w}}}\right)\left(1-C_{b, w} \sqrt{\frac{d_{1}}{t_{w}}}\right)\left(1+C_{b, \mathrm{I}} \sqrt{\frac{I_{b}}{t_{w}}}\right)\left(1+C_{b, b} \sqrt{\frac{b_{f}}{t_{w}}}\right)
$$

where, $C_{b}$ =general coefficient, $C_{b, r}, C_{b, w}, C_{b, l}$ and $C_{b, b}$ are the coefficients of inside bent radius to thickness ratio, web slenderness ratio, bearing length to thickness ratio and flange width to thickness ratio, respectively.

Another approach to determine the buckling load is to use GBT based software as was done by Natario et al. [38,39] or a finite strip analysis based software, THIN-WALL-2 develoepd and used by Nguyen et al. [38] recently.

\section{Yield Load $\left(R_{b, y}\right)$}

Yield/plastic load $\left(R_{b, y}\right)$ determination is difficult because of the complex web crippling failure. Different approaches used by past studies have been mainly based on experimentally and/or numerically observed post-failure yield line mechanisms. Initially a simple plastic mechanism model was used in Young and Hancock [12], followed by Choy et al. [33] and Keerthan and Mahendran [34] who assumed a 45 degree load distribution from the loading plate to web midheight to calculate the yield/plastic load $\left(R_{b y}\right)$ without including the effect of corners. Natário et al. $[35,36]$ improved this approach and derived a predictive equation in the form of 
Eq. (10) for the yield load using idealised plastic mechanisms for ETF and ITF load cases, where $N_{m}$ is the yield mechanism length given by Eq. (11). Natário et al. [35,36] also proposed yield mechanism length $\left(N_{m}\right)$ for channel sections using the load dispersion slope of the concentrated load through the corners to be 1:2.5 and 1:1 through the web for ETF load case and increased load dispersion slope to 1:1.5 through the web for ITF load case. Sundararajah et al. [16] and Sundarajah [21] proposed simplified yield mechanisms as shown in Figs. 12 and 13 for lipped channel sections under two-flange and one-flange load cases and derived yield load equation (Eq. 10) based on enery required to form plastic hinges, similar to Natário et al. [35,36]. However, Sundararajah et al. [16] and Sundarajah [21] proposed different load dispersion slopes based on finite element analyisis at ultimate failure load. The same approach then extended to other sections such as unlipped channels and SupaCees in the studies reported here [15-21].

$$
\begin{aligned}
& \begin{array}{l}
R_{b, y}=f_{y} N_{m}\left(\sqrt{4 r_{m}^{2}+t_{w}{ }^{2}}-2 r_{m}\right) \\
N_{m}=I_{b}+a\left(2.5 r_{e x t}+x d_{1}\right) \\
\text { where } r_{m}=r_{i}+t_{w} / 2 \text { (inside bent radius from mid-thickness line) and } \\
\qquad r_{e x t}=r_{i}+t_{w} \text { (external bent radius) }
\end{array}
\end{aligned}
$$

The coefficients a and x are needed to determine $N_{m}$ from Eq. (11), where a is 1 or 2 depending on whether it is one-flange or two-flange loading. However, the coefficient $\mathrm{x}$ relates to the load dispersion slope $(1: x)$, for which a series of finite element analyses was undertaken in each case with relatively thicker sections but with varying inside bent radius and yield strength. Figs. 14 and 15 show the typical ultimate failure modes for one and two-flange load cases from FE analyses. They were then used to determine the average yield mechanism length $\left(N_{m}\right)$ and thus corresponding $\mathrm{x}$ values for each of the three sections and four load cases and the recommended a and $\mathrm{x}$ values are given in Table 8 .

\section{DSM Equations}

Although several past studies [32,35-36] recommended Eq. (7) with three factors that were determined by calibrating against experimental and numerical results, the standard DSM format is based on the fore factor $\left(n_{3}\right)$ being equal to one. The studies reported here have therefore developed suitable DSM equations in the required standard format for web crippling 
for three different sections (unlipped and lipped channels and SupaCees) under four load cases. Using the extensive web crippling capacity $\left(R_{b}\right)$ data from experiments and FE analyses, buckling loads $\left(R_{b, c r}\right)$ from Eqs. (8) and (9) and yield loads $\left(R_{b, y}\right)$ from Eqs. (10) and (11), suitable coefficients $n_{1}$ and $n_{2}$ were determined for the DSM based Eqs. (12) and (13) and are presented in Table 9. Figs. 16 to 19 demonstrate a good agreement with the proposed DSM curves for lipped channel and SupaCee sections for one-flange and two-flange load cases. Furter details are given in [15-21]. In proposed DSM equations, the zone labelled as a yielding failure (Region A) in Figs 16 and 17 has inelastic reserve capacity, which has not considered in simple plastic mechanism proposed by Young and Hancock [12].

$$
\begin{array}{ll}
\text { When } \lambda \leq \lambda_{\mathrm{y}} & \frac{R_{b}}{R_{b, y}}=1 \\
\text { When } \lambda>\lambda_{\mathrm{y}} & \frac{R_{b}}{R_{b, y}}=\left[1-n_{1}\left(\frac{R_{b, c r}}{R_{b, y}}\right)^{n_{2}}\right]\left(\frac{R_{b, c r}}{R_{b, y}}\right)^{n_{2}}
\end{array}
$$

Web crippling slenderness $\quad \lambda=\sqrt{\frac{R_{b, y}}{R_{b, c r}}}$

\subsection{Conclusions}

This paper has provided a summary of the detailed web crippling studies of lipped and unlipped channel sections with unfastened to supports, SupaCee sections unfastened to supports and unlipped channel sections fastened to supports and their important outcomes. These studies were based on both experimental and finite element studies. In all the web crippling experimental studies, specimen lengths and test set-ups were chosen carefully based on the guidelines given in the recently updated AISI S909 standard test method for web crippling. Comparison of experimental web crippling capacities with predictions using the current coldformed steel specifications such as AISI S100 [1], AS/NZS 4600 [2] and Eurocode 3 Part 1-3 [3] showed that Eurocode predicted the web crippling capacities of thin-lipped and unlipped channels accurately for two-flange load cases, underestimated them for one-flange load cases and overestimated for other sections. AS/NZS 4600 and AISI S100 design equation predicted the web crippling capacities inconsistently in most cases. Accurate web crippling coefficients were proposed for use with the unified web crippling equation in AS/NZS 4600 and AISI S100 for all the considered sections based on experimental studies. 
Finite element models were then developed, analysed using quasi-static analysis and validated using experimental results. Finite element parametric studies followed to extend the applicability of proposed coefficients for lipped channel sections with unfastened to supports and unlipped channel sections with fastened supports. The proposed coefficients to AS/NZS 4600 and AISI S100 design equation were then revised using the parametric study results. A material yield strength factor was proposed and included in the current web crippling design equation with suitable coefficients for lipped channel sections with unfastened supports and unlipped channel sections with fastened supports. Direct Strength Method (DSM) based equations were also proposed for lipped and unlipped channel and SupaCee sections for all four load cases. Suitable equations have also been proposed to determine the two important components of DSM, the critical buckling and yield loads of these sections. The findings from the studies reported in this paper can be included in the future versions of cold-formed steel design standards.

\section{Acknowledgements}

The authors gratefully acknowledge the financial support from Australian Research Council and the research and technical support provided by Queensland University of Technology.

\section{References}

[1] American Iron and Steel Institute (AISI), Specifications for the cold-formed steel structural members, cold-formed steel design manual, AISI S100, Washington DC, USA, 2012.

[2] Standards Australia/Standards New Zealand (SA), Australia/New Zealand Standard AS/NZS 4600 Cold-formed steel structures, Sydney, Australia, 2018.

[3] Euro code 3 Part 1.3 (ECS), Design of Steel Structures: Part 1.3: General Rules Supplementary rules for cold-formed thin gauge members and sheeting, European Committee for Standardization, Brussels, Belgium, 2006.

[4] American Iron and Steel Institute, Standard test method for determining the web crippling strength of cold-formed steel beams, AISI S909, Washington DC, USA, 2013.

[5] Hetrakul, N., and Yu, W.W. (1978), Structural behaviour of beam webs subjected to web crippling and a combination of web crippling and bending, Final Report, Civil Engineering Study 78-4, University of Missouri-Rolla, Rolla, Missouri, U.S.A. 
[6] Bhakta, B.H., LaBoube, R.A. and Yu, W.W. (1992), The effect of flange restraint on web crippling strength, Final Report, Civil Engineering Study 92-1, University of MissouriRolla, Rolla, Missouri, U.S.A

[7] Cain, D.E., LaBoube, R.A. and Yu, W.W. (1995), The effect of flange restraint on web crippling strength of cold-formed Steel Z-and I-sections, Final Report, Civil Engineering Study 95-2, University of Missouri-Rolla, Rolla, Missouri, U.S.A.

[8] Gerges, R.R. and Schuster, R.M. (1998), Web crippling of single web cold-formed steel members subjected to End-One-Flange loading, Proc of 14th International Specialty Conference on Cold-formed Steel Structures, St. Louis, Missouri, U.S.A.

[9] Prabakaran, K. (1993), “Web Crippling of Cold-formed Steel Sections”, Project Report, Department of Civil Engineering, University of Waterloo, Ontario, Canada.

[10] Prabakaran and Schuster (1998), Web crippling of cold-formed steel sections, Proc. of 14th International Speciality Conference on Cold-formed Steel Structures, St. Louis, Missouri, USA.

[11] Beshara, B. and Schuster, R.M. (2000), Web crippling of cold-formed steel C and Z sections, Proc. of 15th International Speciality Conference on Cold-Formed Steel Structures, St.Louis, Missouri, U.S.A.

[12]Young, B. and Hancock, G., Design of cold-formed channels subjected to web crippling, Journal of Structural Engineering, 2001; 127: 1137-1144.

[13] Macdonald, M., Heiyantuduwa, M. A., Kotelko, M. and Rhodes, J., Web crippling behaviour of thin-walled lipped channel beams, Thin-Walled Structures, 2011; 49: 682690.

[14]Macdonald, M. and Heiyantuduwa, M. A., A Design rule for web crippling of cold-formed steel lipped channel beams based on nonlinear FEA”, Thin-Walled Structures, 2012; 53: 123-130.

[15] Sundararajah, L., Mahendran, M. and Keerthan, P. (2016) Experimental Studies of Lipped Channel Beams Subject to Web Crippling under Two Flange Load Cases, ASCE J. of Structural Engineering, 2016; 142 (9): 04016058.

[16] Sundararajah, L., Mahendran, M. and Keerthan, P., Web Crippling Experiments of High Strength Lipped Channel Beams under One-Flange Loading, Journal of Constructional Steel Research, 2017; 138: 851-866.

[17] Sundararajah, L., Mahendran, M. and Keerthan, P. (2017) Web Crippling Studies of SupaCee Sections under Two Flange Load Cases, Engineering Structures, 2017; 153: 582597. 
[18] Sundararajah, L., Mahendran, M. and Keerthan, P. Design of SupaCee Sections Subject to Web Crippling under One-Flange Load Cases, ASCE J of Structural Engineering, 2018; 144 (12), https://doi.org/10.1061/(ASCE)ST.1943-541X.0002206

[19] Sundararajah, L., Mahendran, M. and Keerthan, P. (2017) New Design Rules for Lipped Channel Beams Subject to Web Crippling under Two-Flange Load Cases, Thin-Walled Structures, 2017;119: 421-437.

[20] Sundararajah, L., Mahendran, M. and Keerthan, P. (2018) Numerical Modelling and Design of Lipped Channel Beams Subject to Web Crippling under One-Flange Load Cases, ASCE Journal of Structural Engineering, Accepted.

[21]Sundararajah, L. (2016), Web crippling studies of cold-formed steel channel beamsexperiments, numerical analyses and design rules, $\mathrm{PhD}$ Thesis, Queensland University of Technology, Brisbane, Australia. https://eprints.qut.edu.au/

[22] Gunalan, S. and Mahendran, M., Web crippling tests of cold-formed unlipped channel sections under two flange load cases, Journal of Constructional Steel Research, 2015; 110: $1-15$.

[23]Gunalan, S. and Mahendran, M. (2019), Web crippling study of unlipped channel beams under one flange load cases, Advanced Steel Construction, In Press

[24] Janarthanan, B., Mahendran, M. and Gunalan, S., Bearing capacity of cold-formed unlipped channel with restrained flanges under EOF and IOF load cases, Steel Construction Design and Research, 2015; 8(3): 146-154.

[25] Janarthanan, B. (2017) Structural Behaviour and Design of Cold-Formed Steel Floor Systems PhD Thesis, Queensland University of Technology, Brisbane, Australia. https://eprints.qut.edu.au/

[26]Simulia, ABAQUS Standard User’s Manual, Version 6.14, Rhode Island, USA, 2013.

[27] Sivakumaran, K.S. (1989), Analysis of Web Crippling Behaviour of Cold-formed Steel Members, Computers and Structures, 1989; 32: 707-719.

[28] Ren, W., Fang, S. and Young, B. Finite-Element Simulation and Design of Cold-Formed Steel Channels Subjected to Web Crippling, Journal of Structural Engineering, 2006; 132(12): 1967-1975.

[29]Kaitila, O. (2004), Web crippling of cold-formed thin-walled steel cassettes, PhD Thesis, Helsinki University of Technology, Finland.

[30]Natário, P., Silvestre, N. and Camotim, D., Web crippling failure using Quasi-static FE Models”, Thin-Walled Structures, 2014; 84: 34-49. 
[31]Natário, P., Silvestre, N. and Camotim, D., Computational modelling of flange crushing in cold-formed steel sections, Thin-Walled Structures, 2014; 84: 393-405.

[32] Duarte, A.P.C. and Silvestre, N., M., A New Slenderness-based Approach for the Web Crippling Design of Plain Channel Steel Beams, International Journal of Steel Structures, 2014; 13: 421-434.

[33] Choy, M.Y., Jia, X.F, Yuan, X., Zhou, J., Wang, H.S. and Yu, C., Direct Strength Method for web crippling of cold-formed steel C- and Z-sections subjected to two-flange loading, Annual Stability Conference of Structural Stability Research Council, Toronto, Canada, 2014; 99-111.

[34] Keerthan, P., Mahendran, M. and Steau, E., Experimental study of web crippling behavior of hollow flange channel beams under two flange load cases, Thin-Walled Structures, 2014; 85 (2): 207-219.

[35] Natário, P., Silvestre, N. and Camotim, D., Direct strength prediction of web crippling failure of beams under ETF loading, Thin-Walled Structures, 2016; 98: 360-374.

[36] Natário, P., Silvestre, N. and Camotim, D., Web crippling of beams under ITF loading: A novel DSM-based design approach, Journal of Constructional Steel Research; 2017; 128, 812-824.

[37] Nguyen, V.V., Hancock, G.J., Pham, C.H., New developments in the direct strength method (DSM) for the design of cold-formed steel sections under localised loading, Steel Construction, 2017; 10 (3): 227-233. DOI: 10.1002/stco.201710028.

[38] Nguyen, V.V., Hancock, G.J., Pham, C.H. Analyses of thin-walled sections under localised loading for general end boundary conditions - Part 2: Buckling, Thin-Walled Structures, 2017;119 (Supplement C): 973-987. 
Table 1: Summary of web crippling tests

\begin{tabular}{|c|c|c|c|c|c|c|c|c|}
\hline Sections & Load case & $\begin{array}{l}\text { Number } \\
\text { tests }\end{array}$ & $d(\mathrm{~mm})$ & $t_{w}(\mathrm{~mm})$ & $r_{i}(\mathrm{~mm})$ & $d_{1} / t_{w}$ & $r_{i} / t_{w}$ & $l_{b} / t_{w}$ \\
\hline \multicolumn{9}{|c|}{ Web crippling tests with flanges unfastened to supports } \\
\hline \multirow{2}{*}{$\begin{array}{l}\text { Unlipped channel sections } \\
\text { [21] }\end{array}$} & ETF/ ITF & 36 & 100 to 200 & 1.2 to 1.5 & 4.0 & 59.4 to 163.6 & 2.6 to 3.4 & 32.7 to 127.1 \\
\hline & $\mathrm{EOF} / \mathrm{IOF}$ & 35 & 100 to 200 & 1.2 to 1.5 & 4.0 & 59.4 to 172.0 & 2.6 to 3.4 & 32.7 to 127.1 \\
\hline \multirow{2}{*}{$\begin{array}{l}\text { Unlipped thick channel } \\
\text { sections }[22,23]\end{array}$} & ETF/ ITF & 42 & 75 to 250 & 3.8 to 6.0 & 4.0 to 8.0 & 15.9 to 39.0 & 0.85 to 1.37 & 4.3 to 32.0 \\
\hline & EOF/ IOF & 21 & 100 to 230 & 3.8 to 6.0 & 4.0 to 8.0 & 21.7 to 35.2 & 0.85 to 1.35 & 8.3 to 39.5 \\
\hline \multirow{2}{*}{$\begin{array}{l}\text { Lipped channel sections } \\
{[15,16]}\end{array}$} & $\mathrm{ETF} / \mathrm{ITF}$ & 36 & 100 to 200 & 1.0 to 2.4 & 3.5 to 5.0 & 58.5 to 116.3 & 2.1 to 3.4 & 10.4 to 97.1 \\
\hline & $\mathrm{EOF} / \mathrm{IOF}$ & 36 & 100 to 200 & 1.0 to 2.4 & 3.5 to 5.0 & 58.5 to 116.3 & 2.1 to 3.4 & 10.4 to 97.1 \\
\hline \multirow{2}{*}{ SupaCee sections $[17,18]$} & ETF/ ITF & 36 & 150 to 250 & 1.0 to 1.9 & 5.0 & 91.0 to 157.7 & 2.6 to 4.9 & 26.2 to 145.6 \\
\hline & $\mathrm{EOF} / \mathrm{IOF}$ & 42 & 150 to 250 & 1.0 to 1.9 & 5.0 & 92.0 to 157.5 & 2.6 to 4.9 & 26.2 to 145.6 \\
\hline \multicolumn{9}{|c|}{ Web crippling tests with flanges fastened to supports } \\
\hline $\begin{array}{l}\text { Unlipped channel sections } \\
\text { [24] }\end{array}$ & $\mathrm{EOF} / \mathrm{IOF}$ & 28 & 100 to 230 & 1.5 to 6.0 & 4.0 to 8.0 & 26.0 to 131.2 & 0.97 to 2.96 & 8.5 to 65.4 \\
\hline
\end{tabular}

Note: $d$ - overall section depth, $t_{w}$ - section/web thickness, $r_{i}$ - inside corner radius, $d_{1}$ - clear web height 
Table 2: Comparison of test results with design standard predictions

\begin{tabular}{|c|c|c|c|c|c|}
\hline \multirow{2}{*}{ Sections } & \multirow{2}{*}{$\begin{array}{c}\text { Load } \\
\text { case }\end{array}$} & \multicolumn{2}{|c|}{$R_{b, E x p} / R_{b, A S N Z S}$} & \multicolumn{2}{|c|}{$R_{b, E x p} / R_{b, E U}$} \\
\hline & & Mean & $\mathrm{COV}$ & Mean & $\mathrm{COV}$ \\
\hline \multicolumn{6}{|c|}{ Two-flange load cases with flanges unfastened to supports } \\
\hline \multirow{2}{*}{ Unlipped channel sections [21] } & ETF & 0.50 & 0.22 & 0.97 & 0.14 \\
\hline & ITF & 2.33 & 0.28 & 1.05 & 0.10 \\
\hline \multirow{2}{*}{ Lipped channel sections [15] } & ETF & 0.62 & 0.13 & 1.10 & 0.14 \\
\hline & ITF & 1.74 & 0.34 & 1.13 & 0.10 \\
\hline \multirow{2}{*}{ SupaCee sections [17] } & ETF & 0.65 & 0.09 & 1.08 & 0.21 \\
\hline & ITF & 2.41 & 0.39 & 1.06 & 0.05 \\
\hline \multirow{2}{*}{ Unlipped thick channel sections [22] } & ETF & 0.85 & 0.07 & 0.75 & 0.06 \\
\hline & ITF & 0.86 & 0.08 & 0.64 & 0.05 \\
\hline \multicolumn{6}{|c|}{ One-flange load case with flanges unfastened to supports } \\
\hline \multirow{2}{*}{ Unlipped channel sections [21] } & EOF & 1.12 & 0.13 & 1.72 & 0.17 \\
\hline & IOF & 1.36 & 0.09 & 1.11 & 0.17 \\
\hline \multirow{2}{*}{ Lipped channel sections [16] } & EOF & 0.91 & 0.13 & 1.70 & 0.16 \\
\hline & IOF & 0.99 & 0.16 & 1.26 & 0.20 \\
\hline \multirow{2}{*}{ SupaCee sections [18] } & EOF & 0.71 & 0.13 & 1.80 & 0.29 \\
\hline & IOF & 1.05 & 0.16 & 1.38 & 0.21 \\
\hline \multirow{2}{*}{ Unlipped thick channel sections [23] } & EOF & 0.80 & 0.11 & 1.23 & 0.06 \\
\hline & IOF & 0.83 & 0.05 & 0.78 & 0.04 \\
\hline \multicolumn{6}{|c|}{ One-flange load case with flanges fastened to supports } \\
\hline \multirow{4}{*}{ Unlipped thick channel sections [24] } & EOF-1 & 1.40 & 0.23 & \multirow{2}{*}{2.18} & \multirow{2}{*}{0.19} \\
\hline & EOF-2 & 0.94 & 0.06 & & \\
\hline & IOF-1 & 1.10 & 0.23 & \multirow{2}{*}{1.00} & \multirow{2}{*}{0.19} \\
\hline & IOF-2 & 0.78 & 0.15 & & \\
\hline
\end{tabular}

\section{Note:}

Design equation in AS/NZS 4600 and AISI S100 is identical and hence referred as AS/NZS 4600 in Table 2

$R_{b, E x p} / R_{b, A S N Z S-:}$ Comparison of test results with AS/NZS 4600 predictions

$R_{b, E x p} / R_{b, E U:}$ Comparison of test results with Eurocode 3 Part 1.3 predictions

EOF-1 \& IOF-1: Coefficients for unlipped channel sections unfastened to supports

EOF-2 and IOF-2: Coefficients for lipped channel sections fastened to supports 
Table 3: Proposed web crippling coefficients for AS/NZS 4600 and AISI S100

\begin{tabular}{|c|c|c|c|c|c|c|c|c|}
\hline Sections & $\begin{array}{l}\text { Load } \\
\text { case }\end{array}$ & $\mathrm{C}$ & $\mathrm{C}_{\mathrm{r}}$ & $\mathrm{Cl}_{1}$ & $\mathrm{C}_{\mathrm{w}}$ & Mean & $\mathrm{COV}$ & $\phi_{\mathrm{w}}$ \\
\hline \multicolumn{9}{|c|}{ Two-flange load cases with flanges unfastened to supports } \\
\hline \multirow{2}{*}{ Unlipped channel sections [21] } & ETF & 3.60 & 0.15 & 0.15 & 0.05 & 1.00 & 0.07 & 0.90 \\
\hline & ITF & 15.60 & 0.25 & 0.01 & 0.001 & 1.00 & 0.08 & 0.89 \\
\hline \multirow{2}{*}{ Lipped channel sections [15] } & ETF & 4.00 & 0.03 & 0.05 & 0.04 & 1.00 & 0.08 & 0.85 \\
\hline & ITF & 17.50 & 0.25 & 0.01 & 0.001 & 1.00 & 0.04 & 0.85 \\
\hline \multirow{2}{*}{ SupaCee sections [17] } & ETF & 3.48 & 0.03 & 0.05 & 0.04 & 1.00 & 0.11 & 0.86 \\
\hline & ITF & 15.60 & 0.25 & 0.01 & 0.001 & 1.00 & 0.07 & 0.89 \\
\hline \multirow{2}{*}{$\begin{array}{l}\text { Unlipped thick channel sections } \\
\text { [22] }\end{array}$} & ETF & 2.93 & 0.19 & 0.26 & 0.05 & 1.00 & 0.05 & 0.91 \\
\hline & ITF & 11.00 & 0.21 & 0.07 & 0.03 & 1.01 & 0.04 & 0.92 \\
\hline \multicolumn{9}{|c|}{ One-flange load case with flanges unfastened to supports } \\
\hline \multirow{2}{*}{ Unlipped channel sections [21] } & EOF & 9.00 & 0.30 & 0.20 & 0.05 & 1.00 & 0.05 & 0.90 \\
\hline & IOF & 14.70 & 0.18 & 0.05 & 0.01 & 1.00 & 0.03 & 0.90 \\
\hline \multirow{2}{*}{ Lipped channel sections [16] } & EOF & 6.30 & 0.10 & 0.10 & 0.02 & 1.00 & 0.07 & 0.90 \\
\hline & IOF & 4.90 & 0.01 & 0.38 & 0.03 & 1.00 & 0.04 & 0.89 \\
\hline \multirow{2}{*}{ SupaCee sections [18] } & EOF & 5.45 & 0.10 & 0.10 & 0.02 & 1.00 & 0.08 & 0.89 \\
\hline & IOF & 4.90 & 0.01 & 0.38 & 0.03 & 1.01 & 0.08 & 0.89 \\
\hline \multirow{2}{*}{$\begin{array}{l}\text { Unlipped thick channel sections } \\
\text { [23] }\end{array}$} & EOF & 9.10 & 0.50 & 0.10 & 0.03 & 1.01 & 0.06 & 0.91 \\
\hline & IOF & 9.00 & 0.20 & 0.10 & 0.01 & 1.01 & 0.05 & 0.91 \\
\hline \multicolumn{9}{|c|}{ One-flange load case with flanges fastened to supports } \\
\hline \multirow{2}{*}{$\begin{array}{l}\text { Unlipped thick channel sections } \\
\text { [24] }\end{array}$} & EOF & 4.50 & 0.15 & 0.25 & 0.015 & 1.00 & 0.06 & 0.90 \\
\hline & IOF & 5.10 & 0.10 & 0.30 & 0.001 & 1.00 & 0.07 & 0.90 \\
\hline
\end{tabular}


Table 4: Details of finite element parametric studies

\begin{tabular}{|l|l|l|l|l|l|l|}
\hline Section & $\begin{array}{l}\text { Load } \\
\text { case }\end{array}$ & $\begin{array}{l}\text { Depth } d \\
\text { (mm) }\end{array}$ & $\begin{array}{l}\text { Thickness } \\
t_{w}(\mathrm{~mm})\end{array}$ & $\begin{array}{l}\text { Inside bent } \\
\text { radius } r_{i} \\
\text { (mm) }\end{array}$ & $\begin{array}{l}\text { Bearing } \\
\text { length } l_{b} \\
\text { (mm) }\end{array}$ & $\begin{array}{l}\text { Yield stress } \\
\text { (MPa) }\end{array}$ \\
\hline $\begin{array}{l}\text { Lipped channel } \\
\text { sections [17-21] }\end{array}$ & $\begin{array}{l}\text { ETF, } \\
\text { ITF, EOF } \\
\text { and IOF }\end{array}$ & 100 to 200 & 1.0 to 2.4 & $0,3,5,7$ & $\begin{array}{l}50,100, \\
150\end{array}$ & $\begin{array}{l}300,450, \\
550\end{array}$ \\
\hline $\begin{array}{l}\text { Unlipped channel } \\
\text { sections with } \\
\text { fastened to } \\
\text { supports [25] }\end{array}$ & $\begin{array}{l}\text { EOF and } \\
\text { IOF }\end{array}$ & 100 to 300 & 1.5 to 6.0 & $4.0,4.5,8.0$ & $\begin{array}{l}50,100, \\
150\end{array}$ & $\begin{array}{l}250,350, \\
450\end{array}$ \\
\hline
\end{tabular}


Table 5: Proposed web crippling coefficients based on finite element parametric studies

\begin{tabular}{|c|c|c|c|c|c|c|c|c|}
\hline Sections & $\begin{array}{l}\text { Load } \\
\text { case }\end{array}$ & $\mathrm{C}$ & $\mathrm{C}_{\mathrm{r}}$ & $\mathrm{C}_{1}$ & $\mathrm{C}_{\mathrm{w}}$ & Mean & $\mathrm{COV}$ & $\phi$ \\
\hline \multicolumn{9}{|c|}{ Two-flange load cases with flanges unfastened to supports } \\
\hline \multirow{2}{*}{ Unlipped channel sections [21] } & ETF & 3.60 & 0.15 & 0.15 & 0.05 & 1.01 & 0.06 & 0.91 \\
\hline & ITF & 15.60 & 0.25 & 0.01 & 0.001 & 1.01 & 0.08 & 0.90 \\
\hline \multirow{2}{*}{ Lipped channel sections [19] } & ETF & 5.35 & 0.22 & 0.23 & 0.06 & 1.00 & 0.20 & 0.76 \\
\hline & ITF & 17.00 & 0.19 & 0.05 & 0.03 & 1.00 & 0.15 & 0.82 \\
\hline \multirow{2}{*}{ SupaCee sections [17] } & ETF & 5.05 & 0.22 & 0.23 & 0.06 & 1.00 & 0.12 & 0.85 \\
\hline & ITF & 14.50 & 0.19 & 0.05 & 0.03 & 1.00 & 0.07 & 0.90 \\
\hline \multirow{2}{*}{$\begin{array}{l}\text { Unlipped thick channel sections } \\
\text { [22] }\end{array}$} & ETF & 2.93 & 0.19 & 0.26 & 0.05 & 1.00 & 0.05 & 0.90 \\
\hline & ITF & 11.00 & 0.21 & 0.07 & 0.03 & 1.01 & 0.04 & 0.90 \\
\hline \multicolumn{9}{|c|}{ One-flange load case with flanges unfastened to supports } \\
\hline \multirow{2}{*}{ Unlipped channel sections [21] } & EOF & 8.8 & 0.30 & 0.20 & 0.05 & 1.00 & 0.05 & 0.90 \\
\hline & IOF & 14.3 & 0.18 & 0.05 & 0.01 & 0.99 & 0.05 & 0.89 \\
\hline \multirow{2}{*}{ Lipped channel sections [20] } & EOF & 7.00 & 0.19 & 0.17 & 0.03 & 1.00 & 0.17 & 0.81 \\
\hline & IOF & 13.10 & 0.22 & 0.13 & 0.01 & 1.00 & 0.17 & 0.80 \\
\hline \multirow{2}{*}{ SupaCee sections [18] } & EOF & 5.95 & 0.19 & 0.17 & 0.03 & 1.00 & 0.10 & 0.87 \\
\hline & IOF & 12.10 & 0.22 & 0.13 & 0.01 & 1.00 & 0.07 & 0.90 \\
\hline \multirow{2}{*}{$\begin{array}{l}\text { Unlipped thick channel sections } \\
\text { [23] }\end{array}$} & EOF & 9.10 & 0.50 & 0.10 & 0.03 & 1.01 & 0.06 & 0.91 \\
\hline & IOF & 9.00 & 0.20 & 0.10 & 0.01 & 1.01 & 0.05 & 0.91 \\
\hline \multicolumn{9}{|c|}{ One-flange load case with flanges fastened to supports } \\
\hline \multirow{2}{*}{$\begin{array}{l}\text { Unlipped thick channel sections } \\
\text { [25] }\end{array}$} & EOF & 1.65 & 0.27 & 1.30 & 0.005 & 1.01 & 0.08 & 0.90 \\
\hline & IOF & 4.60 & 0.23 & 0.52 & 0.001 & 1.00 & 0.082 & 0.89 \\
\hline
\end{tabular}


Table 6: Proposed web crippling coefficients for the modified AS/NZS 4600 equation

\begin{tabular}{|c|c|c|c|c|c|c|c|c|c|}
\hline \multirow{2}{*}{ Sections } & \multirow{2}{*}{$\begin{array}{l}\text { Load } \\
\text { case }\end{array}$} & $\mathrm{C}$ & $\mathrm{C}_{\mathrm{r}}$ & $\mathrm{C}_{\mathrm{l}}$ & $\mathrm{C}_{\mathrm{w}}$ & $\mathrm{C}_{\mathrm{s}}$ & Mean & $\mathrm{COV}$ & $\phi_{\mathrm{w}}$ \\
\hline & & \multicolumn{8}{|c|}{ Sections with flanges unfastened to supports } \\
\hline \multirow{4}{*}{$\begin{array}{l}\text { Lipped channel sections } \\
{[15,16,19,20]}\end{array}$} & EOF & 1.30 & 0.19 & 0.13 & 0.04 & 8.1 & 1.00 & 0.11 & 0.86 \\
\hline & IOF & 2.60 & 0.22 & 0.12 & 0.01 & 5.5 & 1.00 & 0.13 & 0.85 \\
\hline & ETF & 1.03 & 0.21 & 0.16 & 0.06 & 6.85 & 1.00 & 0.13 & 0.85 \\
\hline & ITF & 1.24 & 0.17 & 0.04 & 0.03 & 16.9 & 1.00 & 0.09 & 0.88 \\
\hline & & \multicolumn{8}{|c|}{ Sections with flanges fastened to supports } \\
\hline \multirow{2}{*}{$\begin{array}{l}\text { Unlipped channel } \\
\text { sections [25] }\end{array}$} & EOF & 1.20 & 0.27 & 1.5 & 0.005 & 0.3 & 1.00 & 0.058 & 0.90 \\
\hline & IOF & 3.50 & 0.26 & 0.6 & 0.001 & 0.3 & 1.00 & 0.064 & 0.90 \\
\hline
\end{tabular}

Note: Eq. 4 is used in [15,16,19,20] and Eq. 6 is used in [25] 
Table 7: Proposed coefficients for buckling coefficient equation ( $k$ )

\begin{tabular}{|c|c|c|c|c|c|c|}
\hline Section & $\begin{array}{c}\text { Load } \\
\text { Case }\end{array}$ & $\mathrm{C}_{\mathrm{b}}$ & $\mathrm{C}_{\mathrm{b}, \mathrm{r}}$ & $\mathrm{C}_{\mathrm{b}, \ell}$ & $\mathrm{C}_{\mathrm{b}, \mathrm{w}}$ & $\mathrm{C}_{\mathrm{b}, \mathrm{b}}$ \\
\hline \multirow{2}{*}{$\begin{array}{c}\text { Unlipped } \\
\text { channel }\end{array}$} & $\mathrm{ETF}$ & 0.59 & 0.01 & 0.40 & 0.05 & 0.01 \\
\cline { 2 - 7 } $\begin{array}{c}\text { sections } \\
{[21]}\end{array}$ & $\mathrm{ITF}$ & 1.39 & 0.01 & 0.10 & 0.03 & 0.05 \\
\cline { 2 - 7 } & $\mathrm{EOF}$ & 1.01 & 0.01 & 0.40 & 0.05 & 0.01 \\
\hline \multirow{2}{*}{$\begin{array}{c}\text { Lipped } \\
\text { channel }\end{array}$} & $\mathrm{IOF}$ & 2.35 & 0.01 & 0.12 & 0.03 & 0.03 \\
\cline { 2 - 7 } $\begin{array}{c}\text { sections } \\
{[19,20]}\end{array}$ & $\mathrm{ETF}$ & 0.58 & 0.01 & 0.30 & 0.05 & 0.05 \\
\cline { 2 - 7 } & $\mathrm{EOF}$ & 0.80 & 0.01 & 0.46 & 0.05 & 0.03 \\
\hline \multirow{2}{*}{$\begin{array}{c}\text { SupaCee } \\
\text { sections }\end{array}$} & $\mathrm{IOF}$ & 3.70 & 0.01 & 0.10 & 0.02 & 0.01 \\
\cline { 2 - 7 }$[17,18]$ & $\mathrm{ETF}$ & 0.62 & 0.01 & 0.30 & 0.05 & 0.05 \\
\cline { 2 - 7 } & $\mathrm{EOF}$ & 0.86 & 0.01 & 0.46 & 0.05 & 0.03 \\
\cline { 2 - 7 } & $\mathrm{IOF}$ & 3.96 & 0.01 & 0.10 & 0.02 & 0.01 \\
\hline
\end{tabular}


Table 8: Proposed coefficients for yield mechanism length $\left(\mathrm{N}_{\mathrm{m}}\right)$

\begin{tabular}{|c|c|c|c|}
\hline Section & Load Case & $\mathrm{a}$ & $\mathrm{x}$ \\
\hline \multirow{3}{*}{$\begin{array}{c}\text { Unlipped channel sections } \\
{[21]}\end{array}$} & $\mathrm{ETF}$ & 1 & 0.35 \\
\cline { 2 - 4 } & $\mathrm{ITF}$ & 2 & 0.75 \\
\cline { 2 - 4 } & $\mathrm{EOF}$ & 1 & 0.90 \\
\cline { 2 - 4 } & $\mathrm{IOF}$ & 2 & 0.90 \\
\hline \multirow{3}{*}{$\begin{array}{c}\text { Lipped channel \& SupaCee } \\
\text { sections [17-20] }\end{array}$} & $\mathrm{ETF}$ & 1 & 0.50 \\
\cline { 2 - 4 } & $\mathrm{ITF}$ & 2 & 0.75 \\
\cline { 2 - 4 } & $\mathrm{EOF}$ & 1 & 0.90 \\
\hline
\end{tabular}


Table 9: Proposed coefficients for DSM Equation

\begin{tabular}{|c|c|c|c|c|c|c|c|}
\hline Section & Load Case & $\lambda_{\mathrm{y}}$ & $\mathrm{n}_{1}$ & $\mathrm{n}_{2}$ & Mean & $\mathrm{COV}$ & $\Phi_{\mathrm{w}}$ \\
\hline \multirow{4}{*}{$\begin{array}{c}\text { Unlipped } \\
\text { channel } \\
\text { sections } \\
\text { [21] }\end{array}$} & ETF & 0.71 & 0.25 & 1.00 & 0.91 & 0.23 & 0.65 \\
\hline & ITF & 0.85 & 0.12 & 0.56 & 1.00 & 0.11 & 0.85 \\
\hline & EOF & 0.69 & 0.25 & 0.90 & 0.94 & 0.15 & 0.75 \\
\hline & IOF & 0.73 & 0.20 & 0.50 & 1.00 & 0.10 & 0.85 \\
\hline \multirow{4}{*}{$\begin{array}{c}\text { Lipped } \\
\text { channel } \\
\text { sections } \\
{[19,20]}\end{array}$} & ETF & 0.71 & 0.25 & 1.00 & 0.90 & 0.16 & 0.75 \\
\hline & ITF & 0.94 & 0.10 & 0.86 & 1.01 & 0.16 & 0.80 \\
\hline & EOF & 0.83 & 0.20 & 0.84 & 1.00 & 0.18 & 0.75 \\
\hline & IOF & 0.78 & 0.23 & 0.85 & 1.00 & 0.23 & 0.70 \\
\hline \multirow{4}{*}{$\begin{array}{c}\text { SupaCee } \\
\text { sections } \\
{[17,18]}\end{array}$} & ETF & 0.72 & 0.25 & 0.98 & 0.99 & 0.16 & 0.80 \\
\hline & ITF & 0.84 & 0.17 & 0.70 & 1.00 & 0.09 & 0.85 \\
\hline & EOF & 0.58 & 0.25 & 0.60 & 1.01 & 0.15 & 0.80 \\
\hline & IOF & 0.82 & 0.17 & 0.59 & 1.01 & 0.17 & 0.80 \\
\hline
\end{tabular}




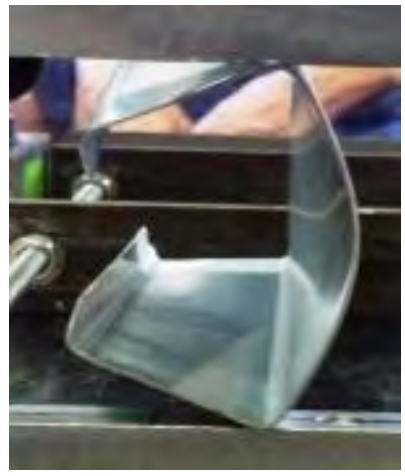

(a) Lipped channel sections

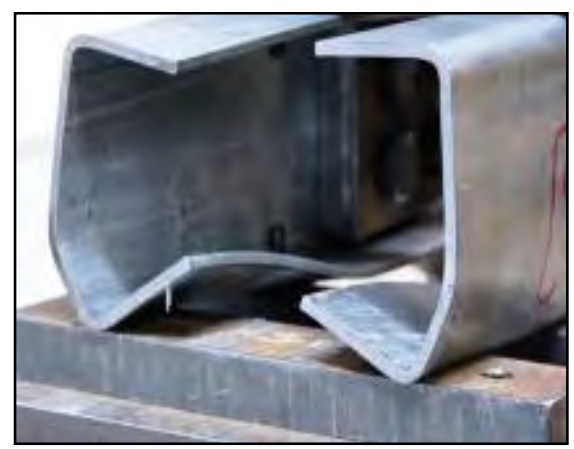

(c) Unlipped channel section with flanges unfastened to support

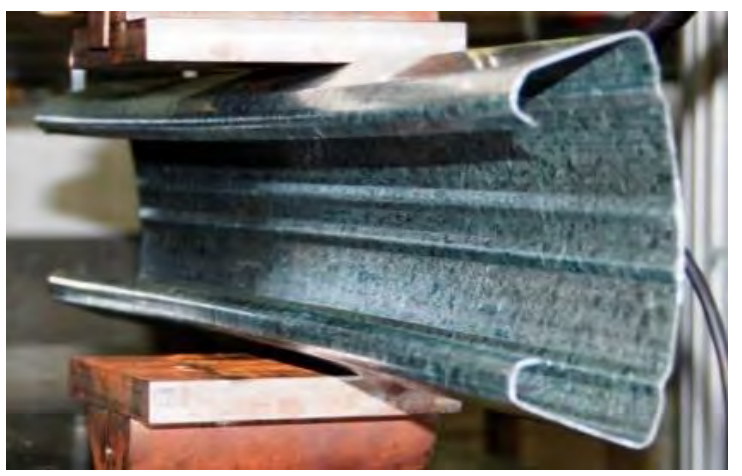

(b) SupaCee sections

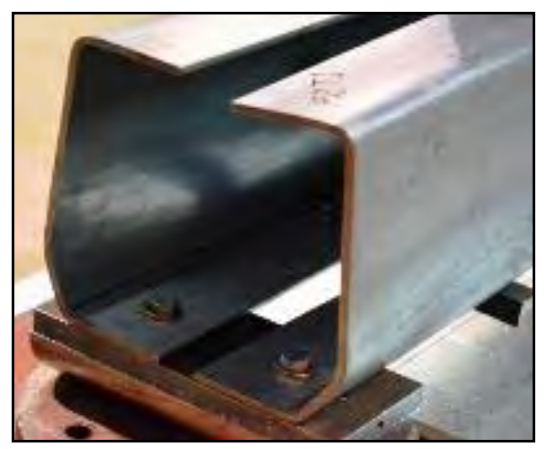

(d) Unlipped channel section with flanges fastened to support

Fig. 1: Web crippling failures of different cold-formed steel sections 


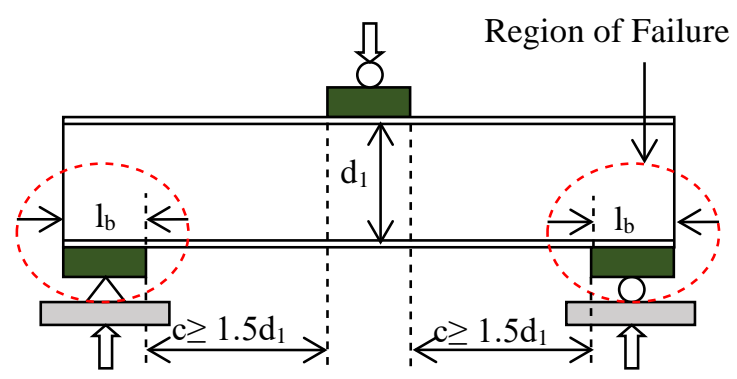

(a) End-One-Flange loading (EOF)

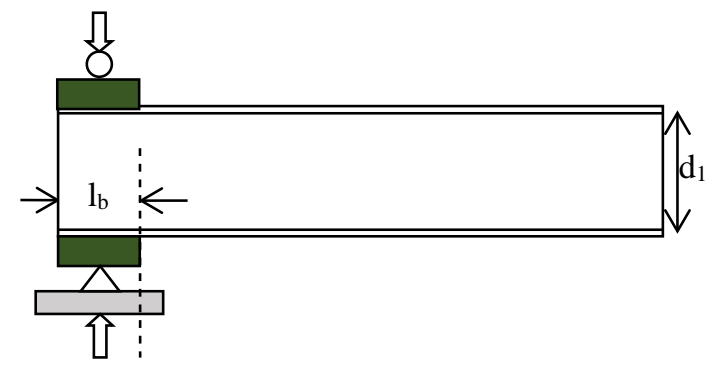

(c) End-Two-Flange loading (ETF)

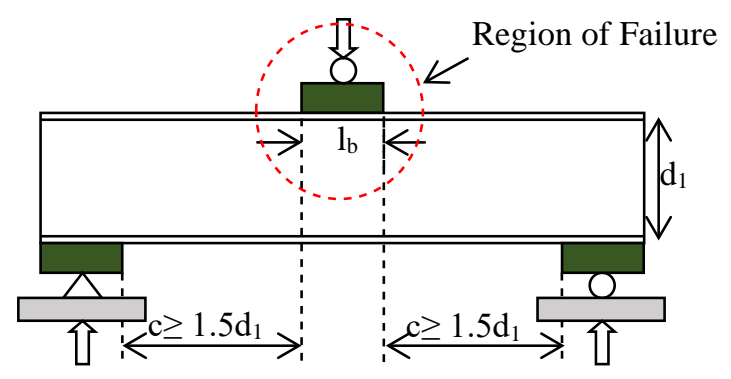

(b) Interior-One-Flange loading (IOF)

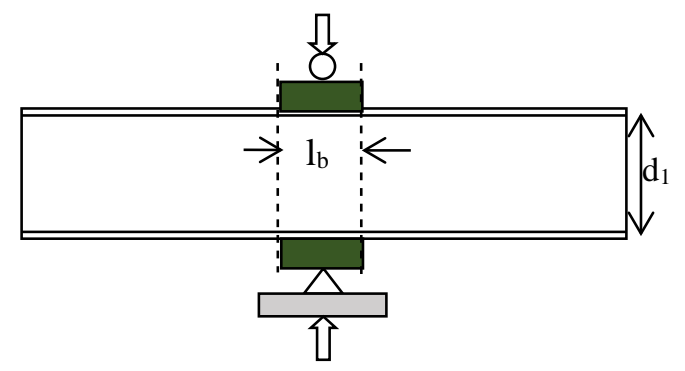

(d) Interior-Two-Flange loading (ITF)

Fig. 2: Load Cases for Web Crippling Tests [4] 


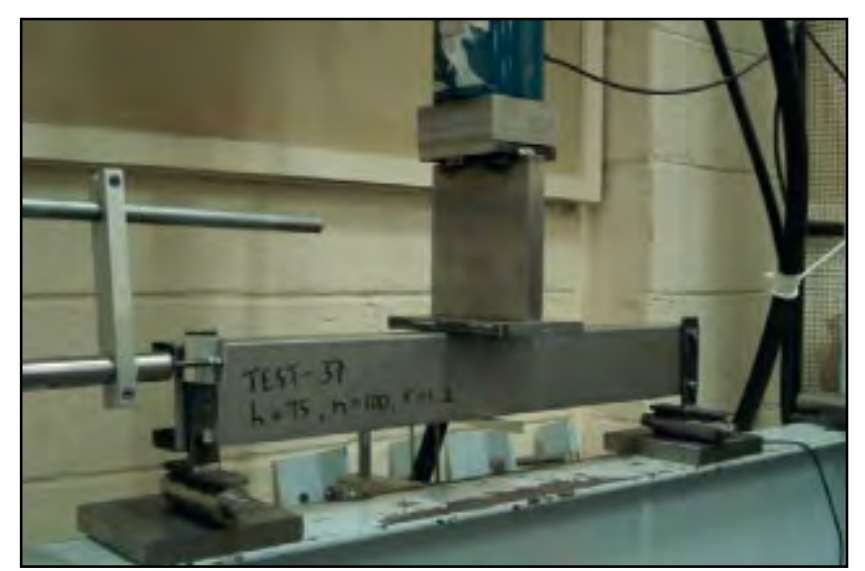

(Macdonald et al. [13])
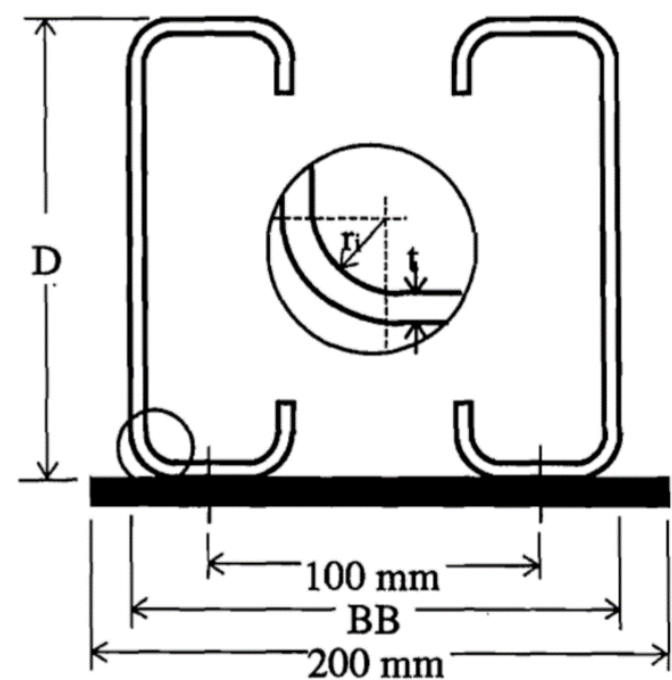

(Gerges and Schuster [8])

Fig. 3: Different web crippling test set-ups

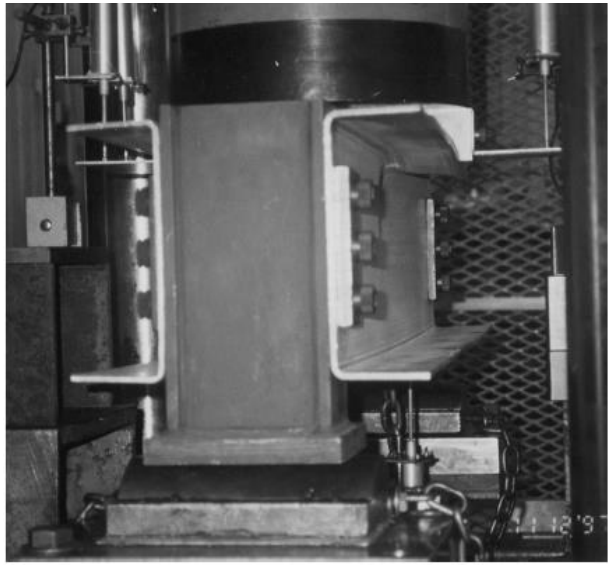

(Young and Hancock [12])

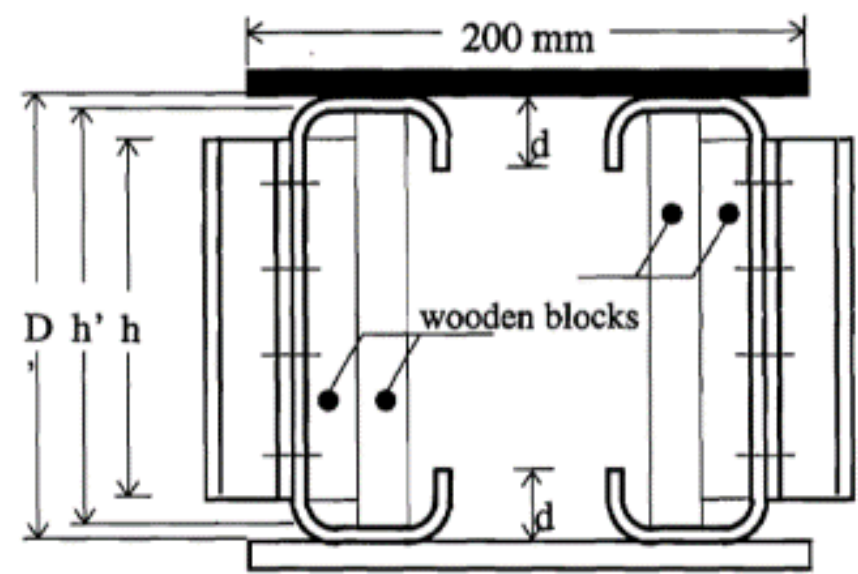

$$
\text { ]) }
$$




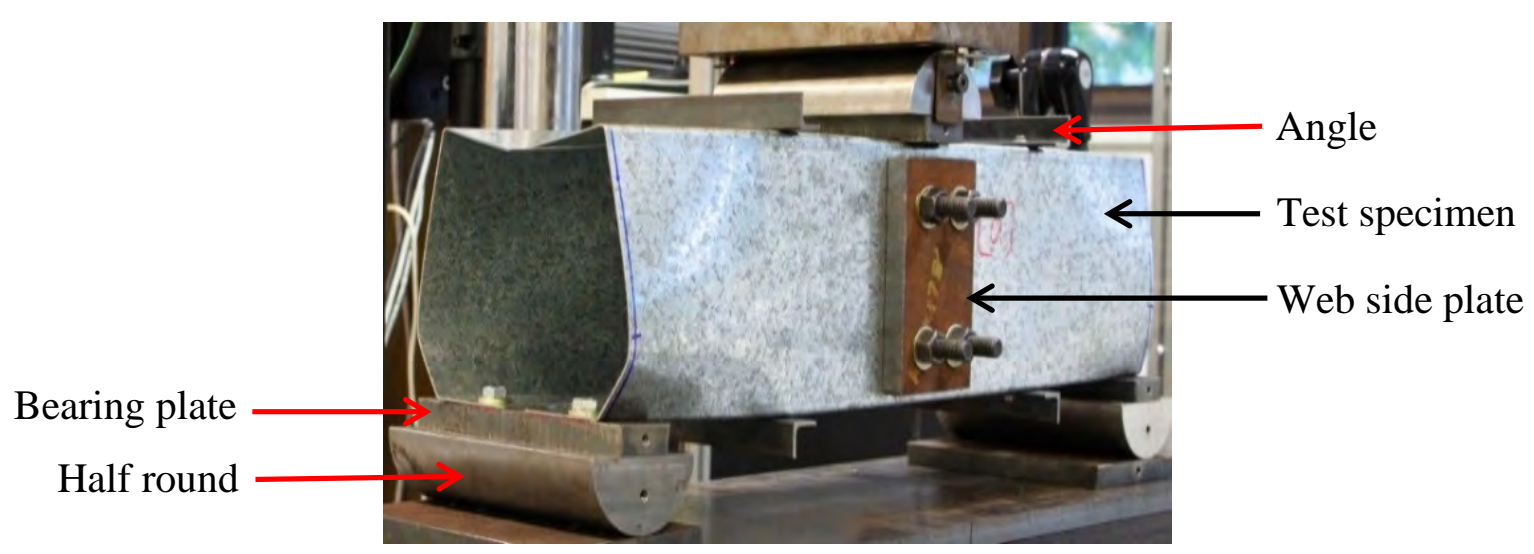

(a) EOF Load case

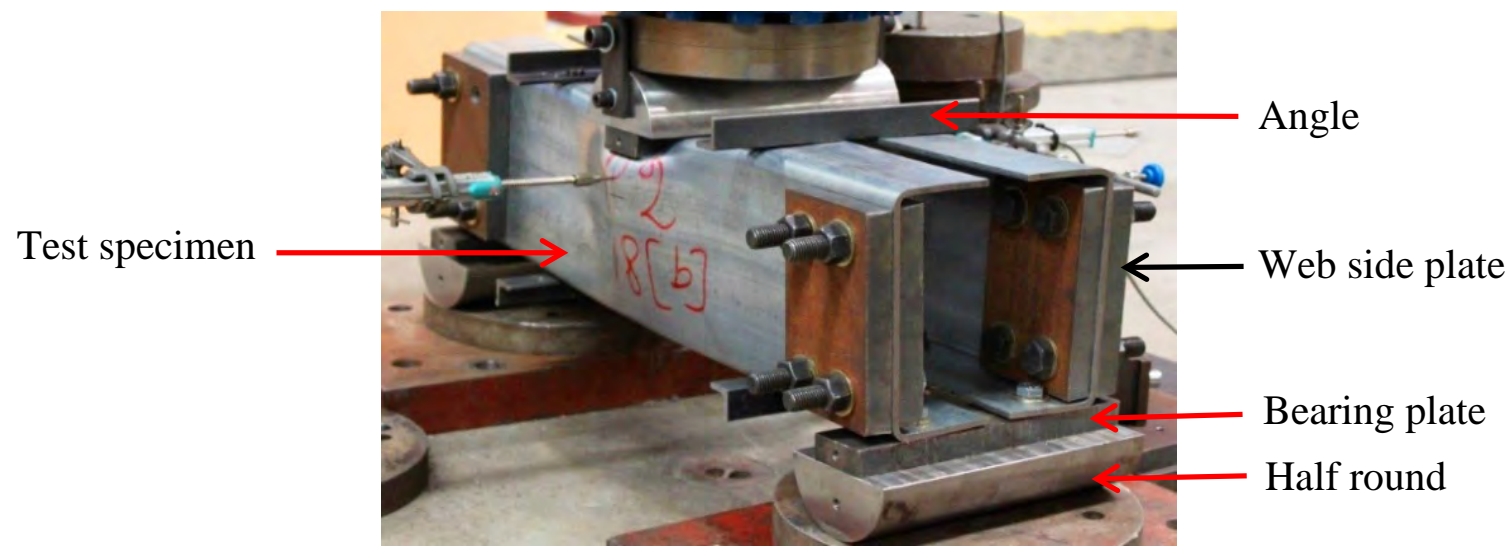

(b) IOF Load case

Fig. 4: Test Set-up for the One-flange load cases [24] 


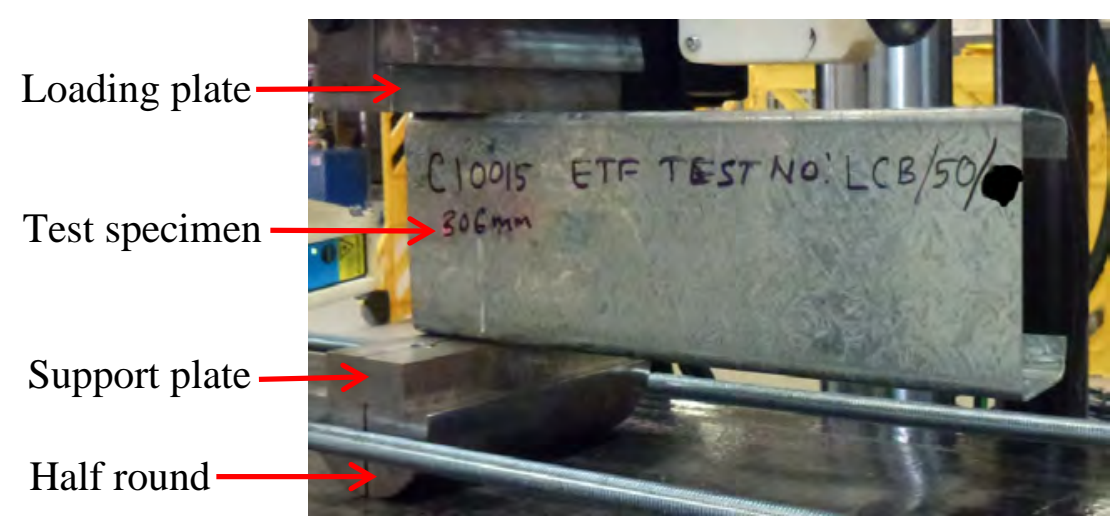

(a) ETF Load case

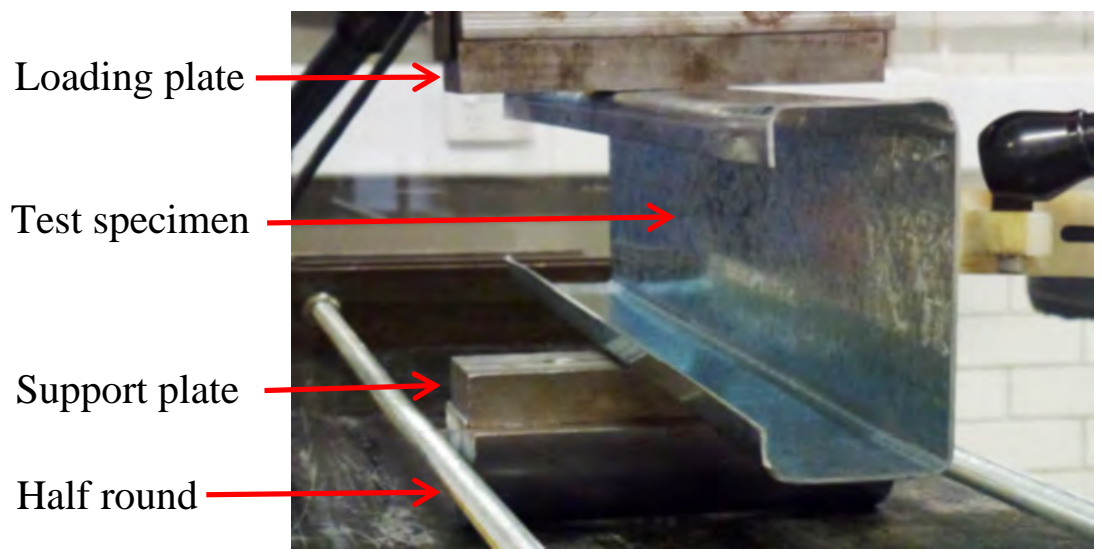

(b) ITF Load case

Fig. 5: Test Set-up for the Two-flange load cases [21] 


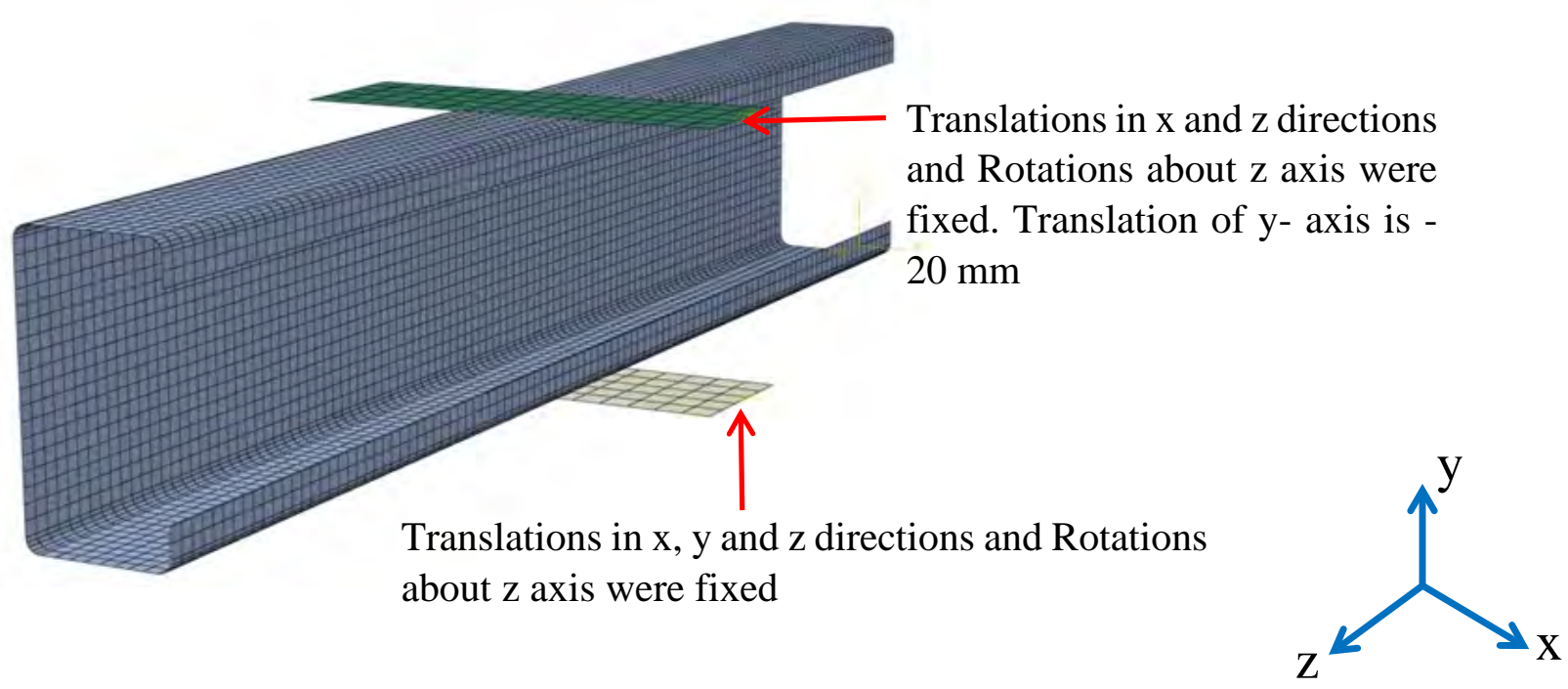

Fig. 6: Boundary conditions of lipped channel sections under ITF load case [21] 
Translations in $\mathrm{x}$ and $\mathrm{z}$ directions and Rotations about $\mathrm{y}$ and $\mathrm{z}$ axes were fixed

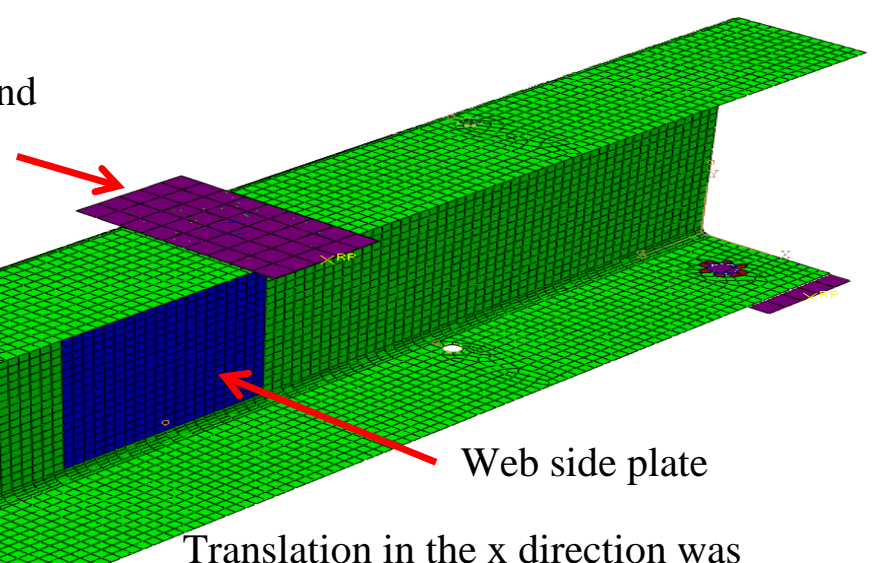

Translation in the $\mathrm{x}$ direction was fixed at $8 \mathrm{~mm}$ hole perimeter

Translations in $\mathrm{x}$ and $\mathrm{y}$ directions and Rotations about $\mathrm{y}$ and $\mathrm{z}$ axes were fixed

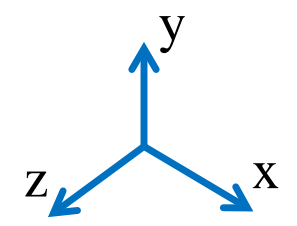

Fig. 7: Boundary conditions of unlipped channel sections under EOF load case [25] 


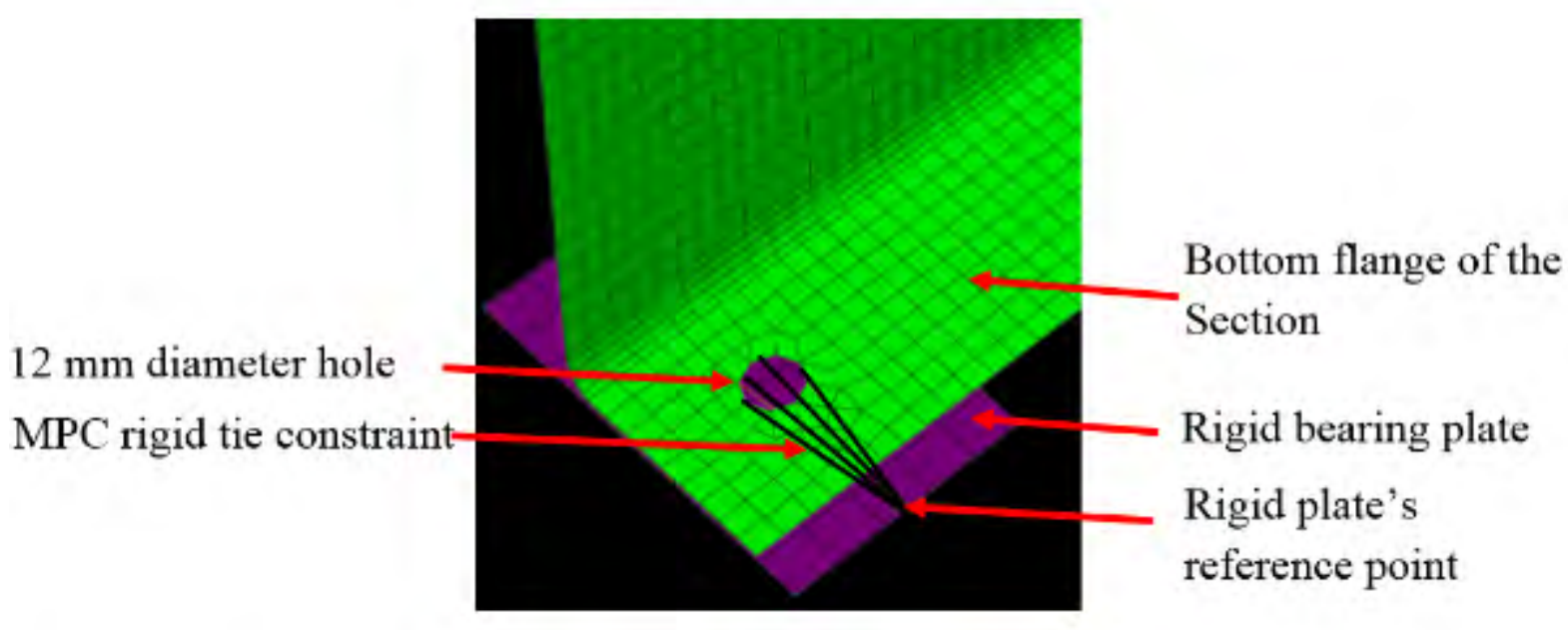

Fig. 8: FE simulation of fastened supports [25] 

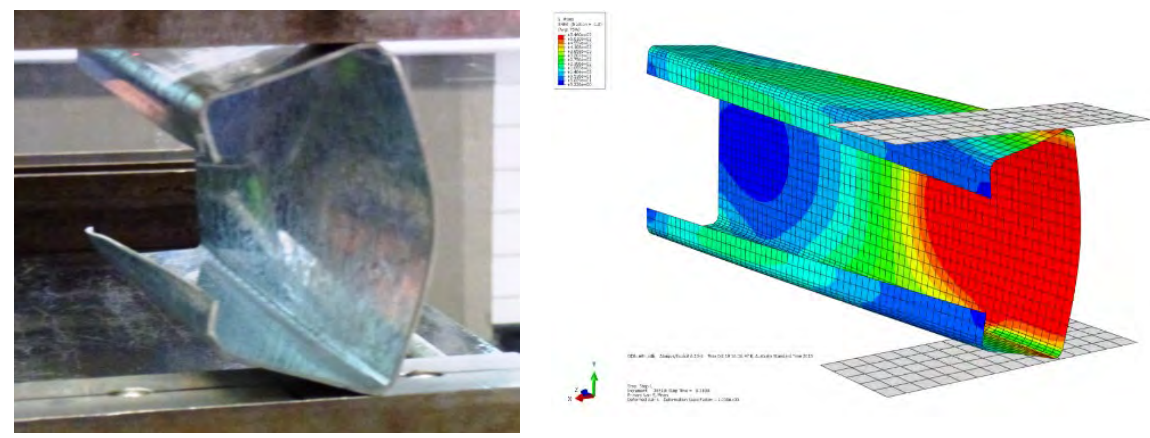

ETF-10015 with $50 \mathrm{~mm}$ bearing plate [21]
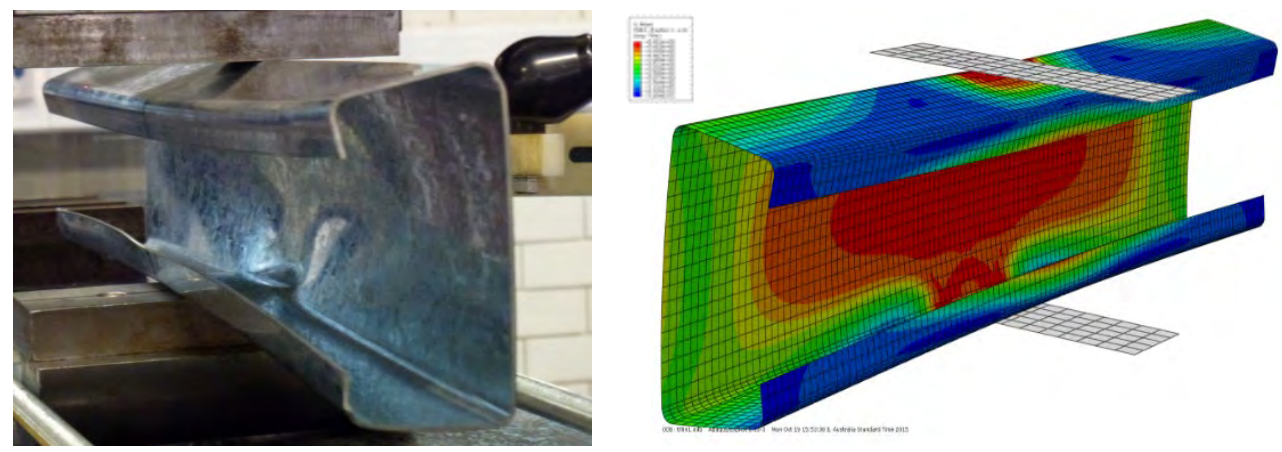

ITF-10015 with $50 \mathrm{~mm}$ bearing plate [21]
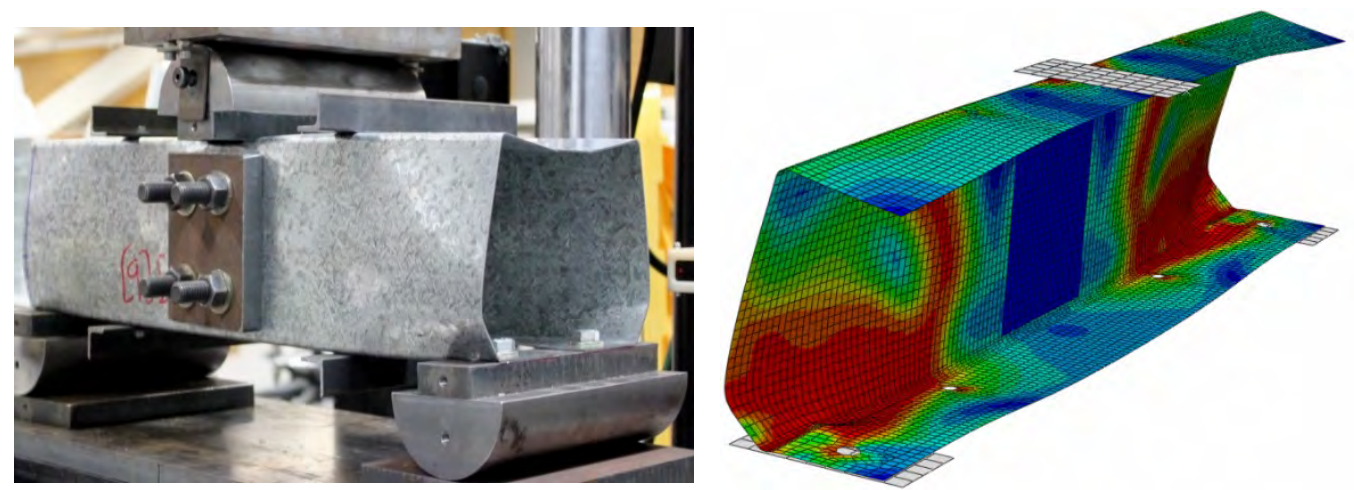

EOF-15015 with $50 \mathrm{~mm}$ bearing plate [25]
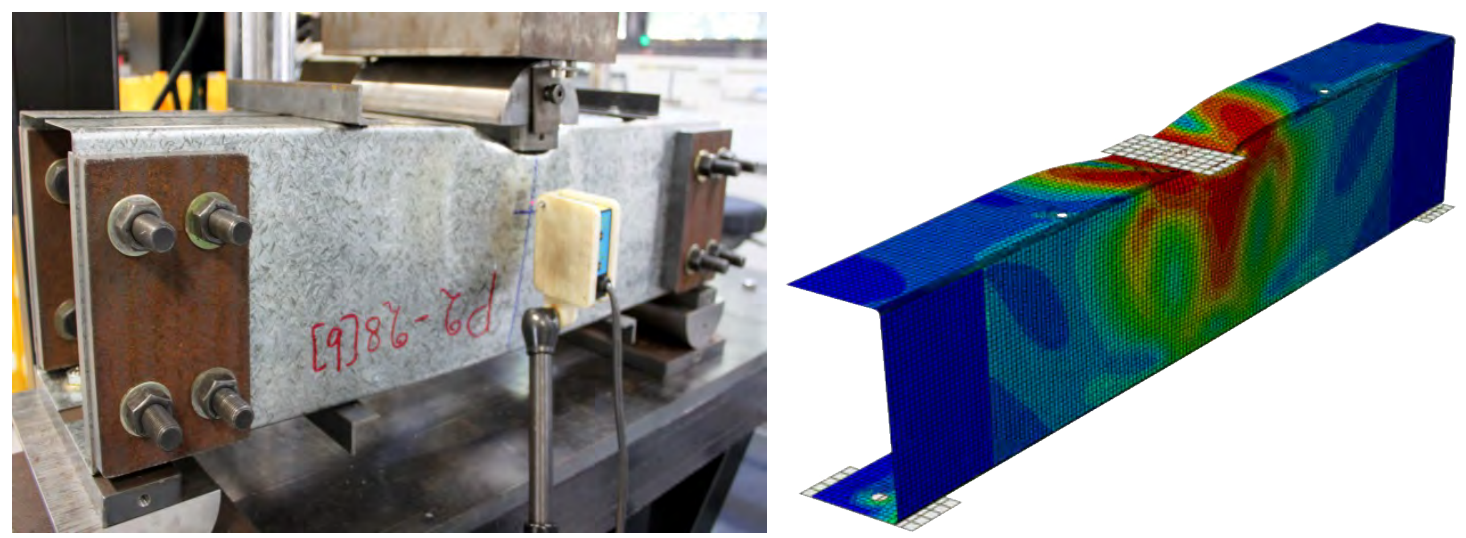

IOF-20015 with $50 \mathrm{~mm}$ bearing plate [25]

Fig. 9: Comparison of failure modes from Tests and FEA 


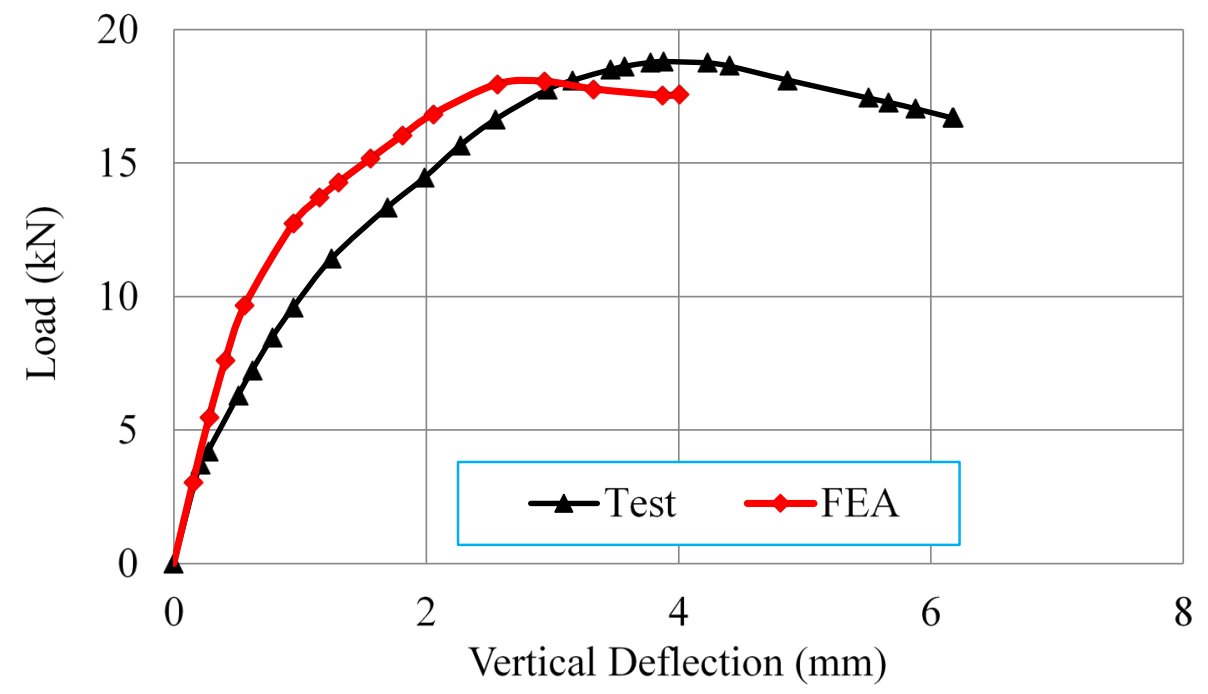

EOF- 10015- bearing length of $50 \mathrm{~mm}$

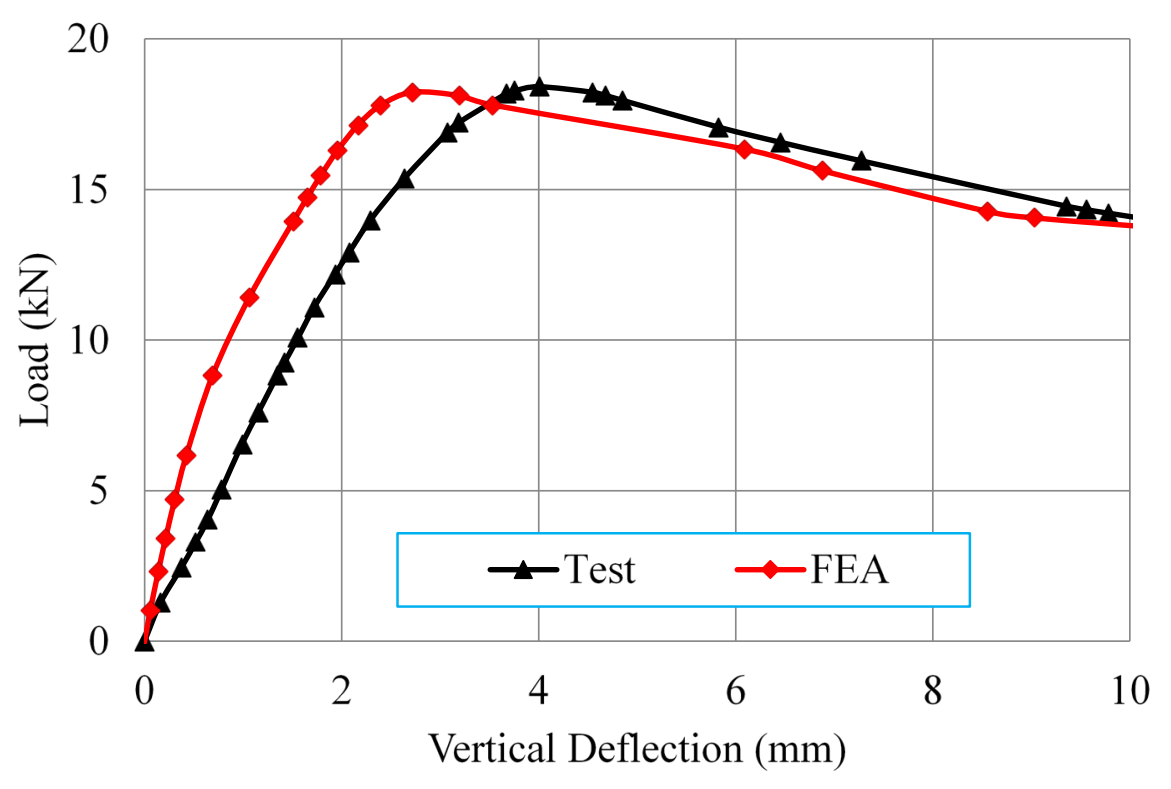

IOF- 20015- bearing length of $100 \mathrm{~mm}$

Fig. 10: Comparison of load versus vertical deflection plots from Tests and FEA 


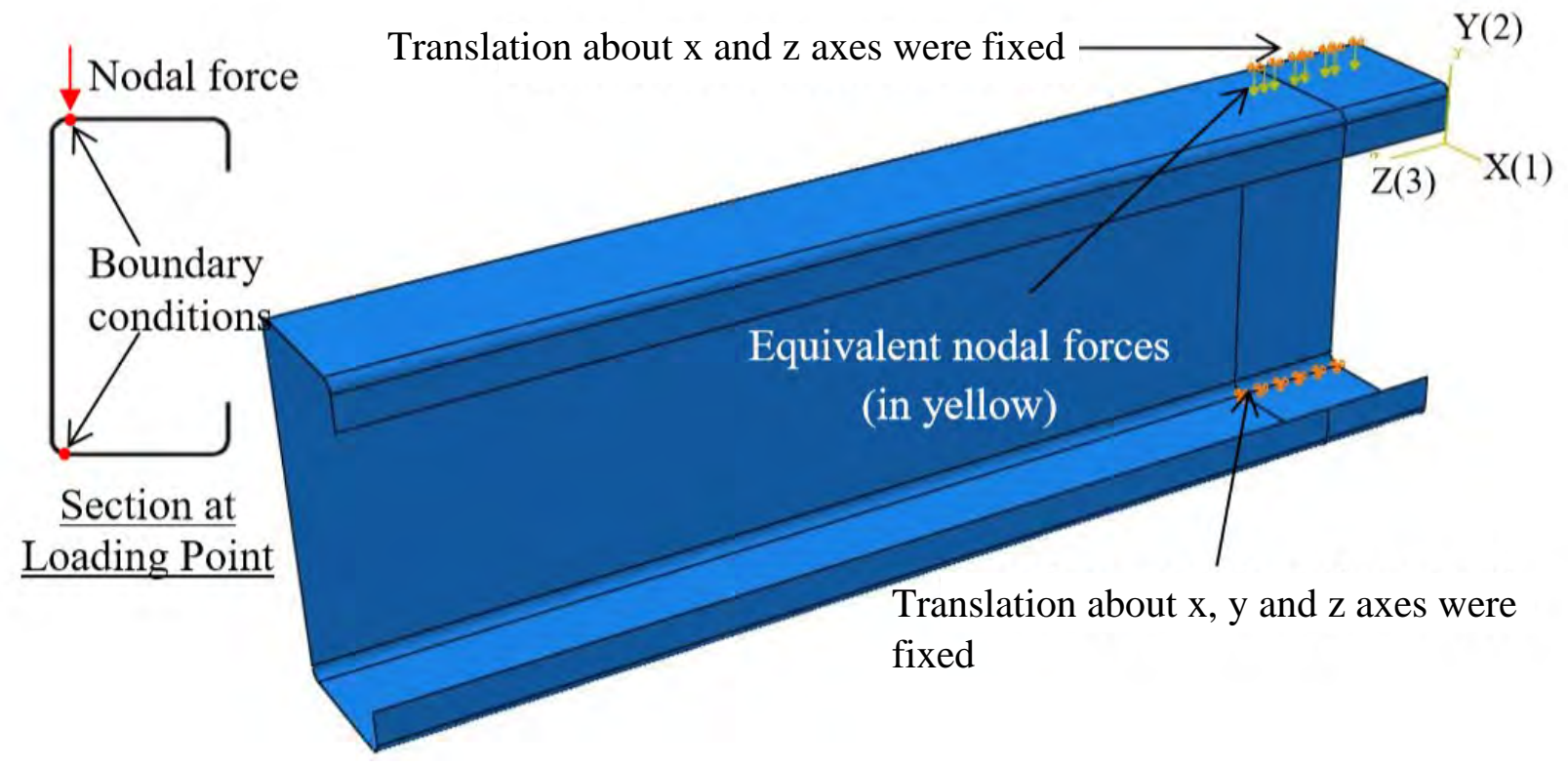

Fig. 11: Elastic buckling analysis of lipped channel sections under ETF load case [21] 

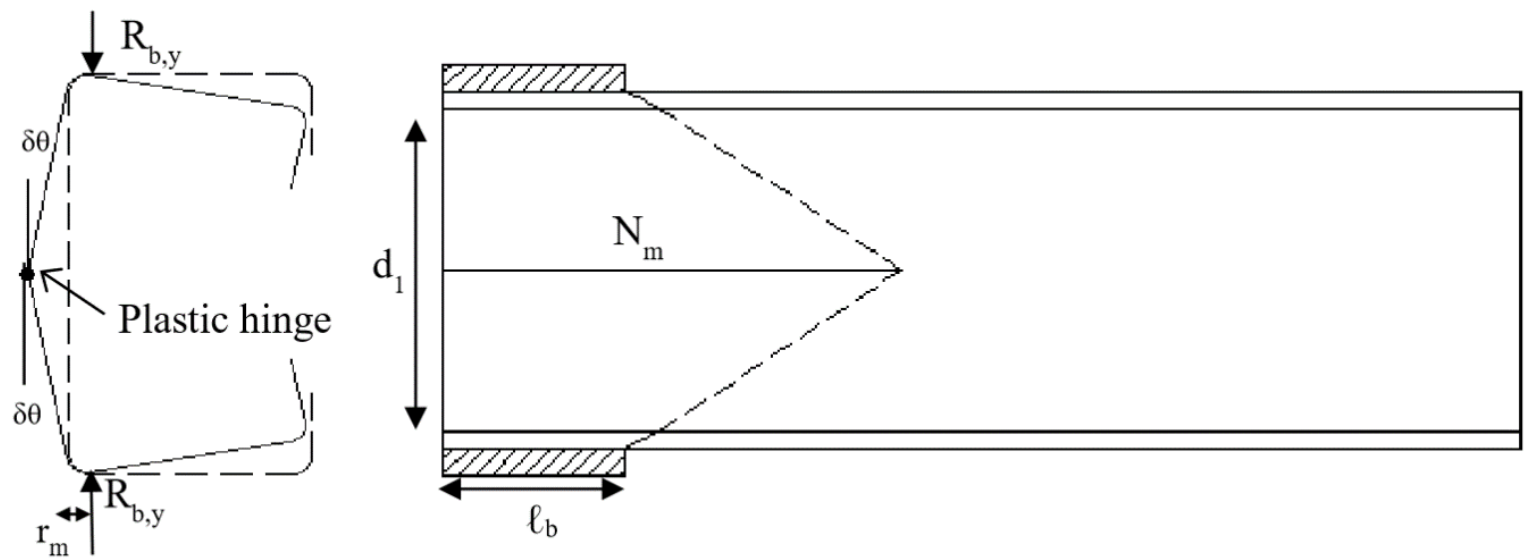

(a) ETF load case
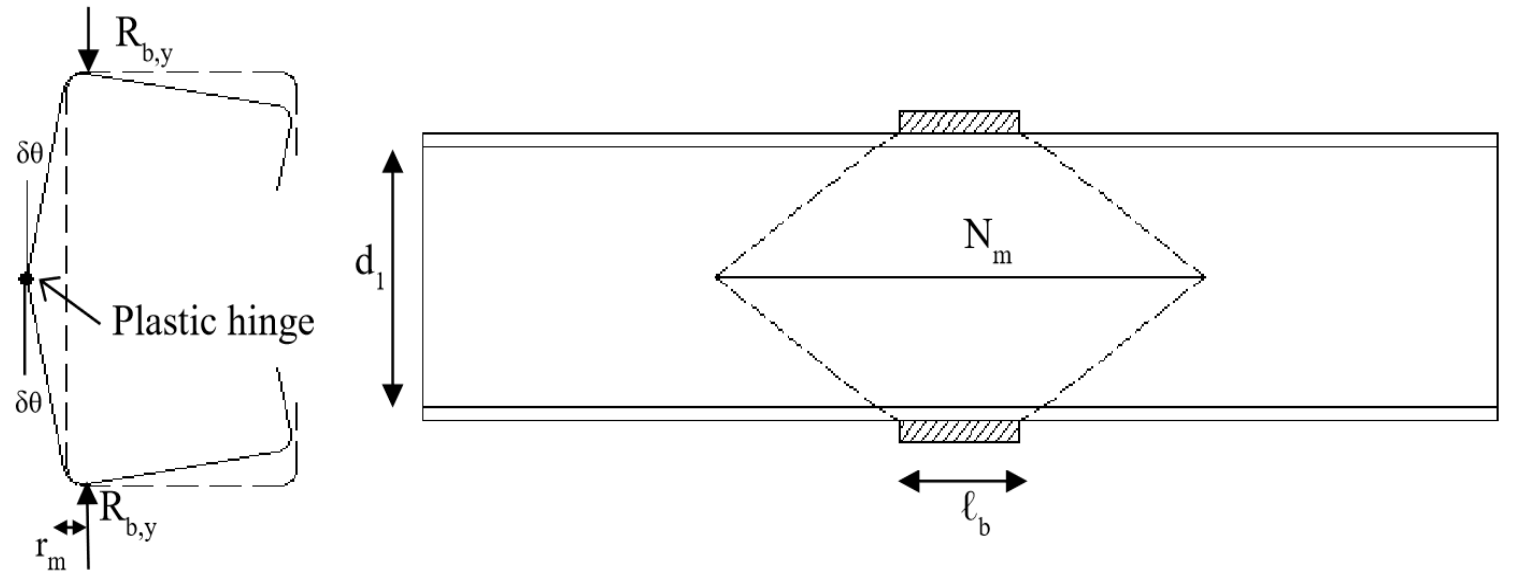

(b) ITF load case

Fig. 12: Plastic mechanism for LCBs under Two-flange load cases [21] 

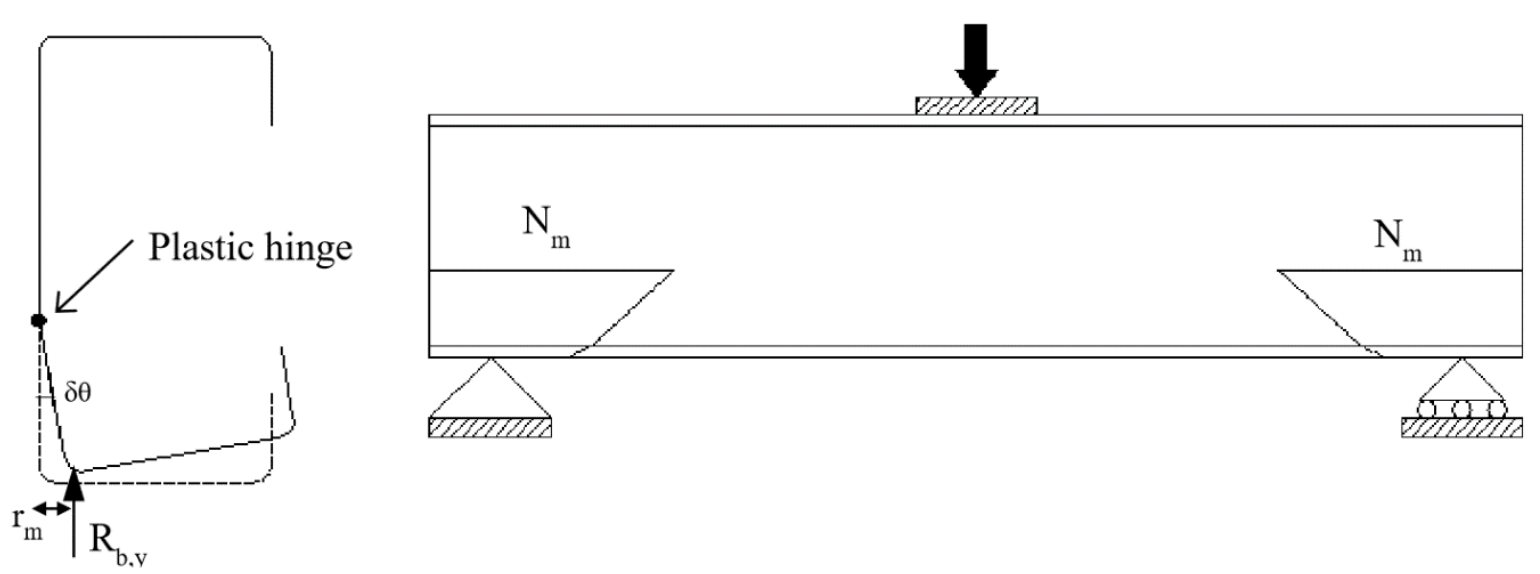

(a) EOF load case

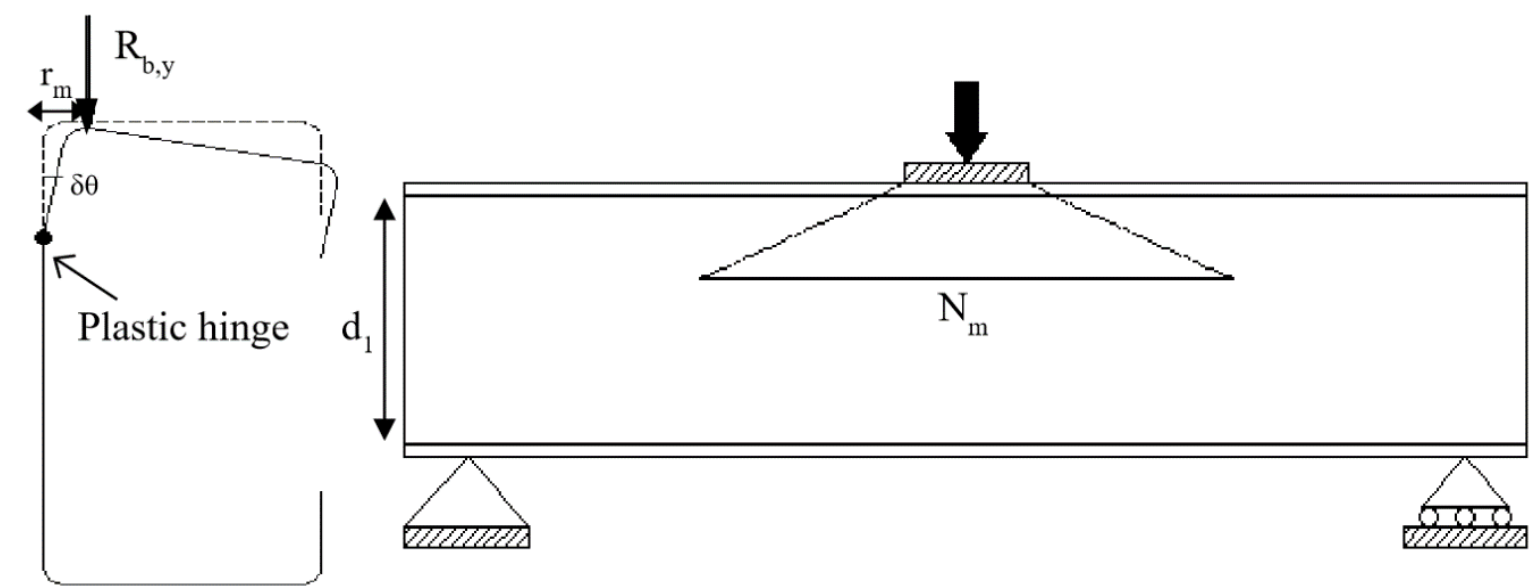

(b) IOF load case

Fig. 13: Plastic mechanism for LCBs under One-flange load cases [16] 

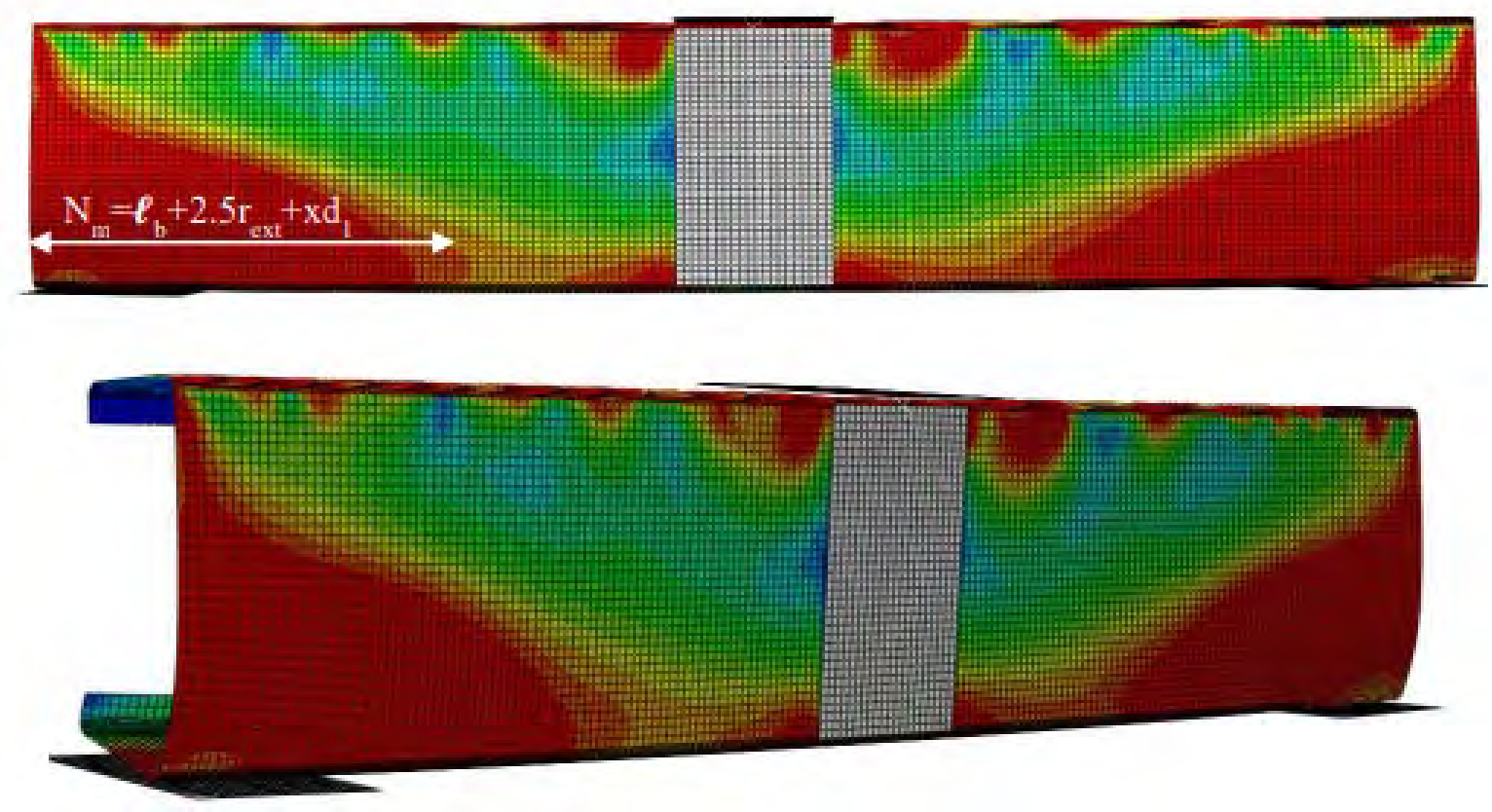

(a) EOF Load Case (C20050, $\left.r_{i}=5 \mathrm{~mm} \mathrm{\&} f_{y}=550 \mathrm{MPa}\right)$
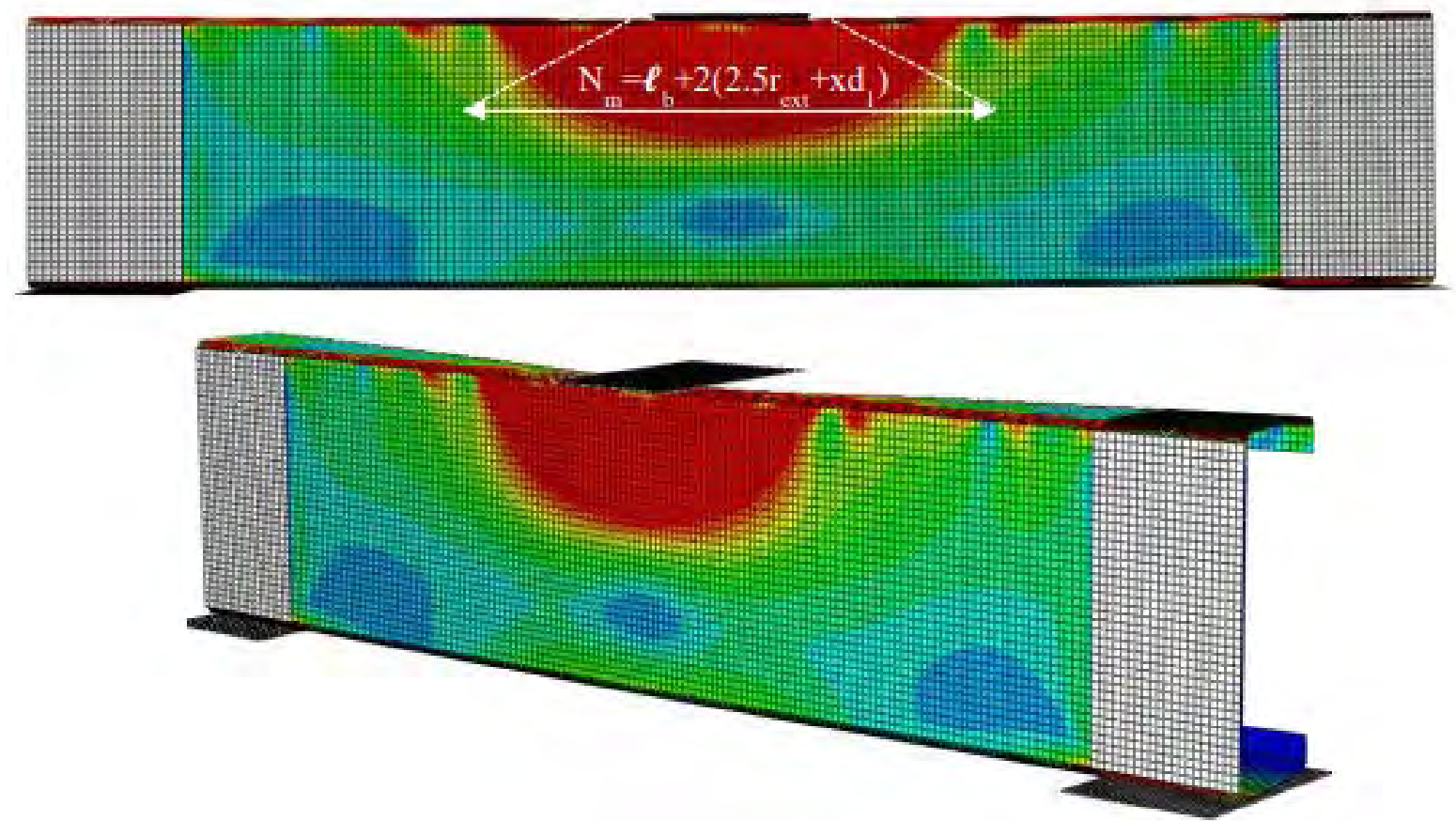

(b) IOF Load Case (C20050, $\left.\mathrm{r}_{\mathrm{i}}=3 \mathrm{~mm} \& \mathrm{f}_{\mathrm{y}}=550 \mathrm{MPa}\right)$

Fig. 14: Yield mechanism length observed with the ultimate failure modes for oneflange load cases [21] 


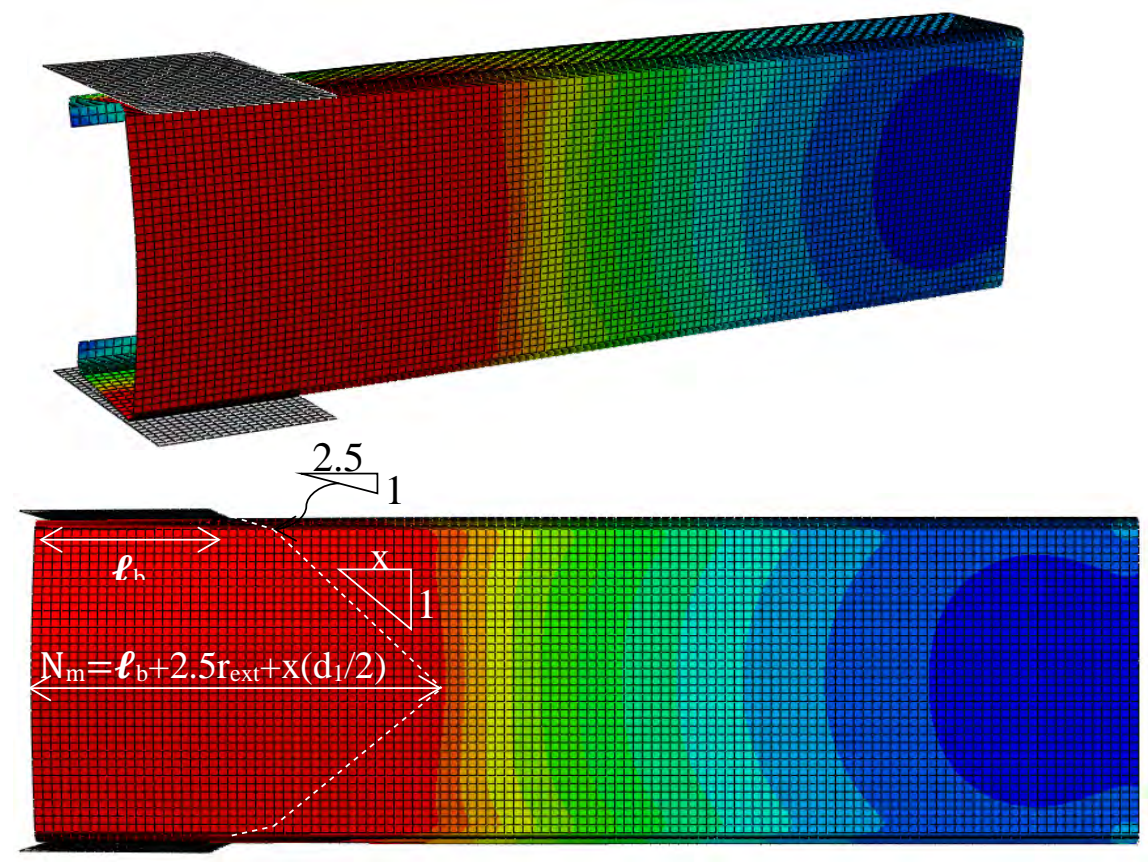

(a) ETF Load Case (C20050, $r_{i}=5$ mm \& $\left.f_{y}=300 \mathrm{MPa}\right)$

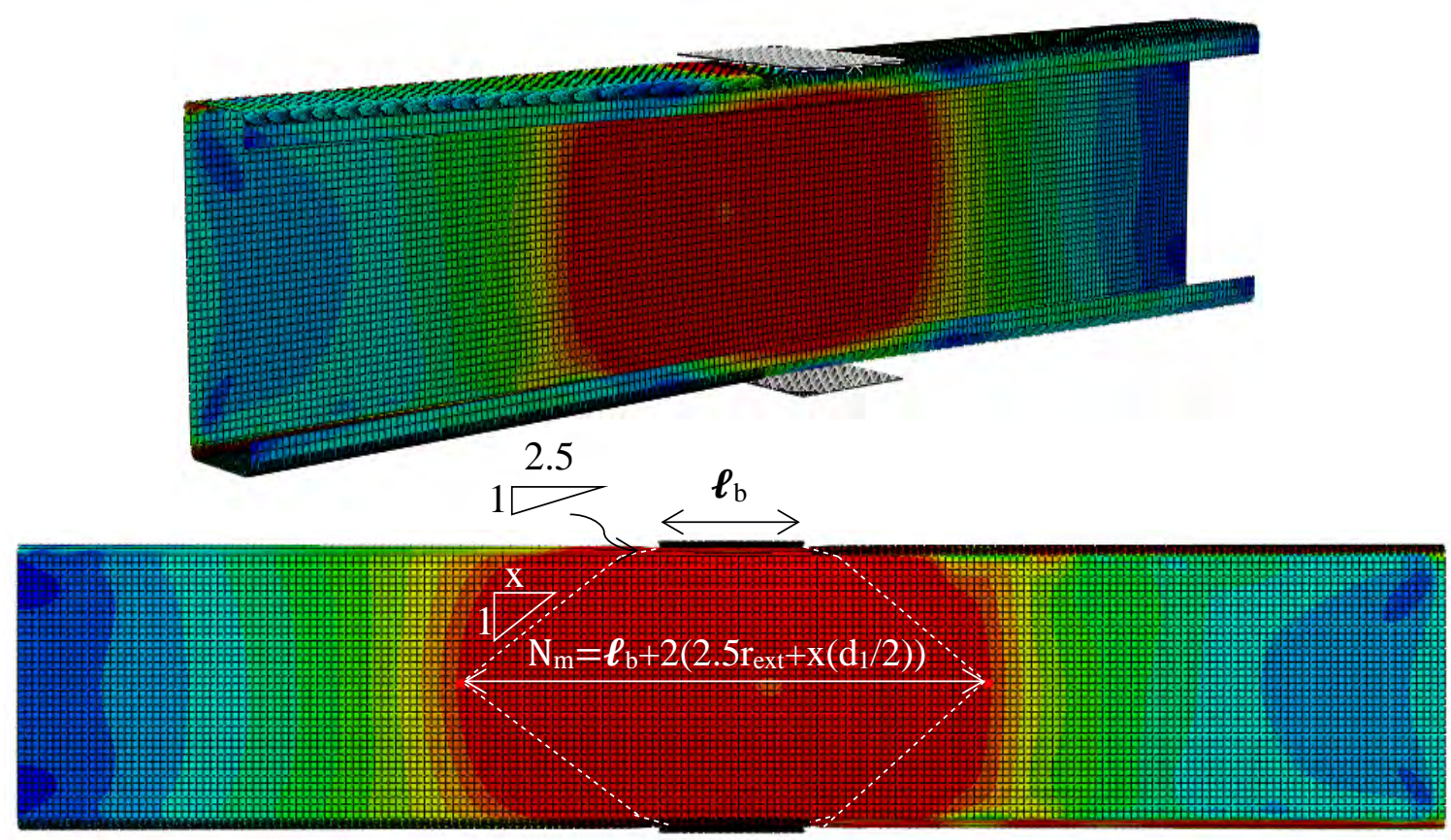

(b) ITF Load Case (C20050, $\left.r_{i}=5 \mathrm{~mm} \& \mathrm{f}_{\mathrm{y}}=300 \mathrm{MPa}\right)$

Fig. 15: Yield mechanism length observed with the ultimate failure modes for twoflange load cases [21] 


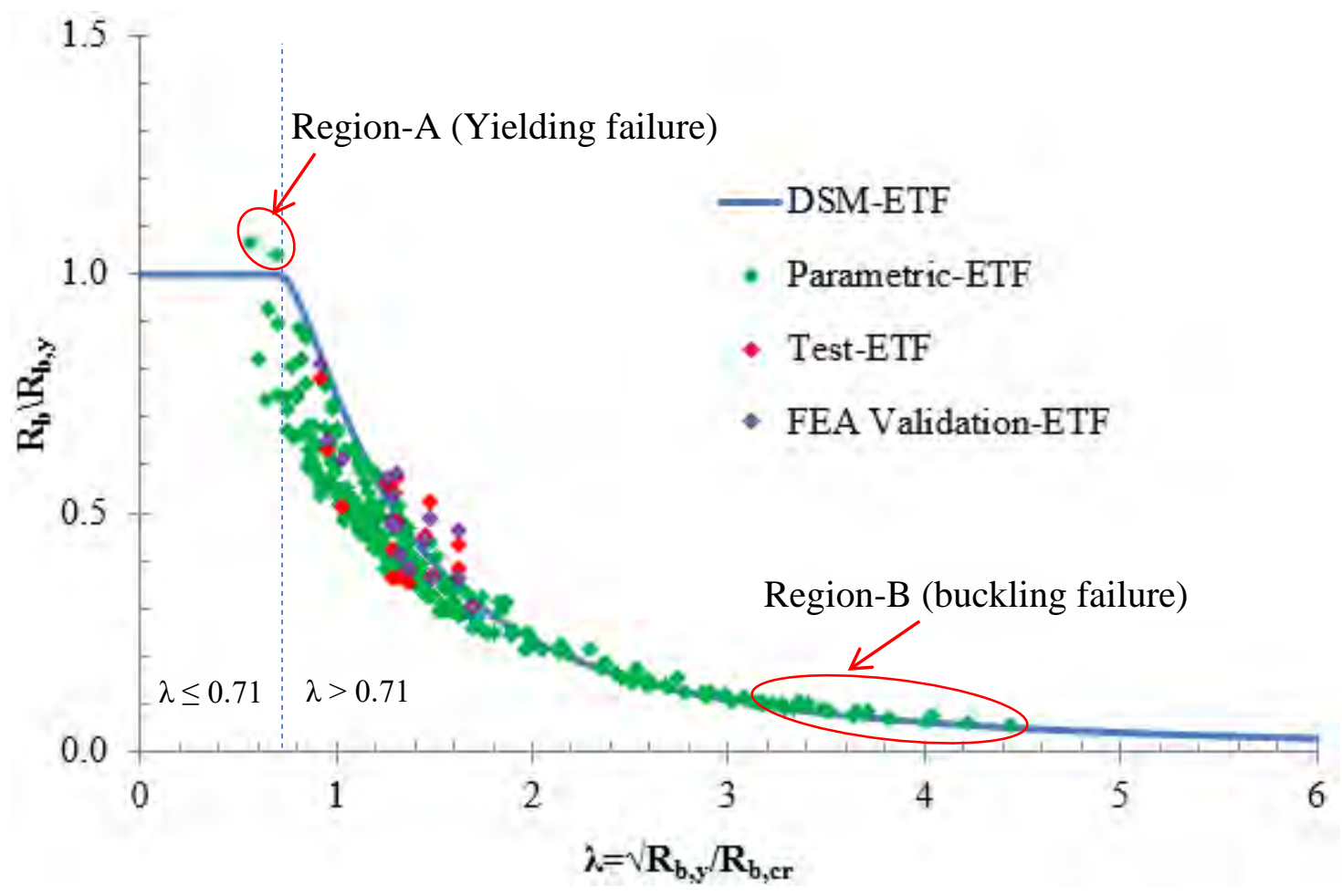

(a) ETF Load Case

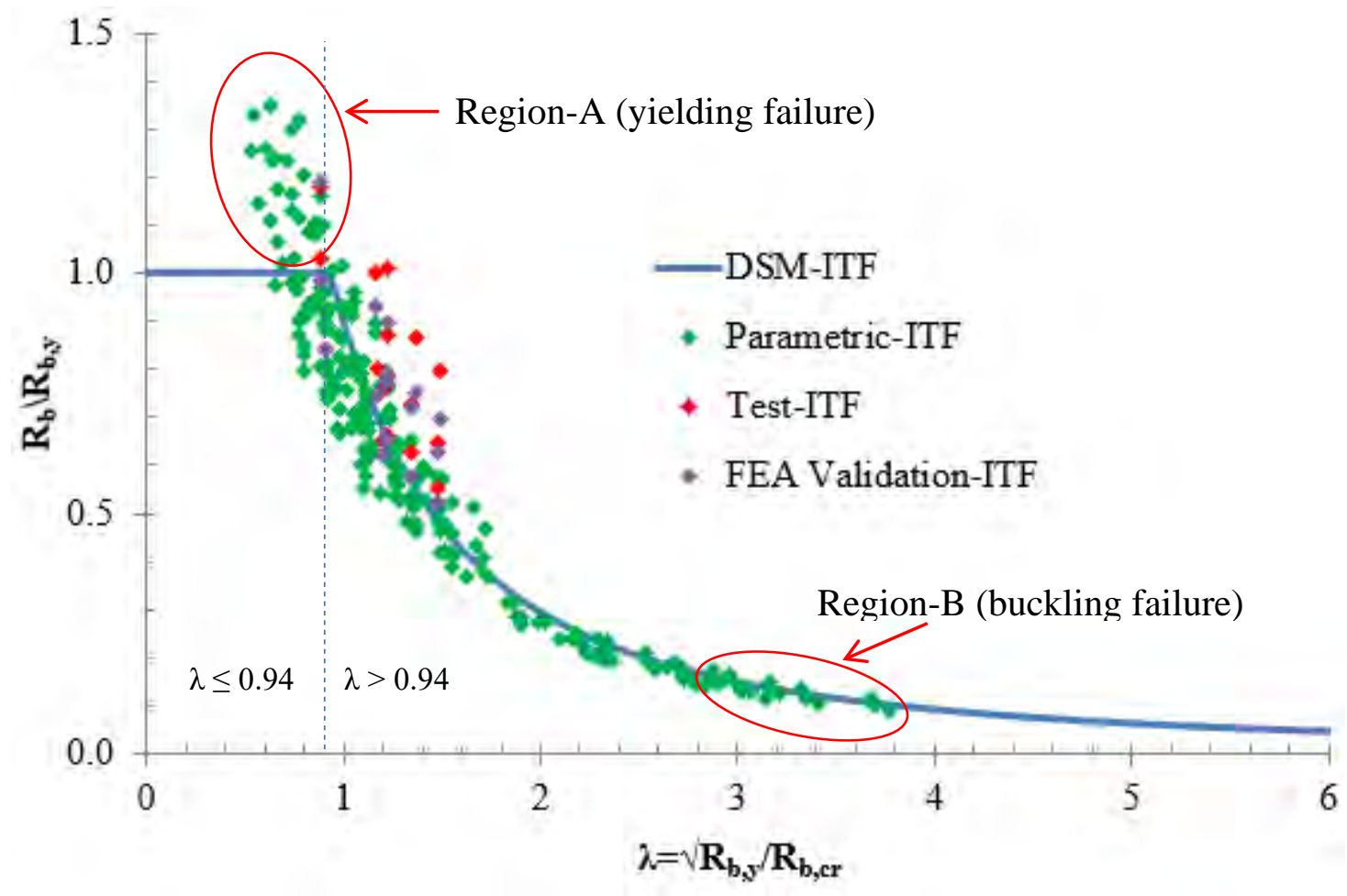

(b) ITF Load Case

Fig. 16: Comparison of web crippling capacities of lipped channels from Test and FEA parametric studies with DSM based design equation- two-flange load cases [21] 


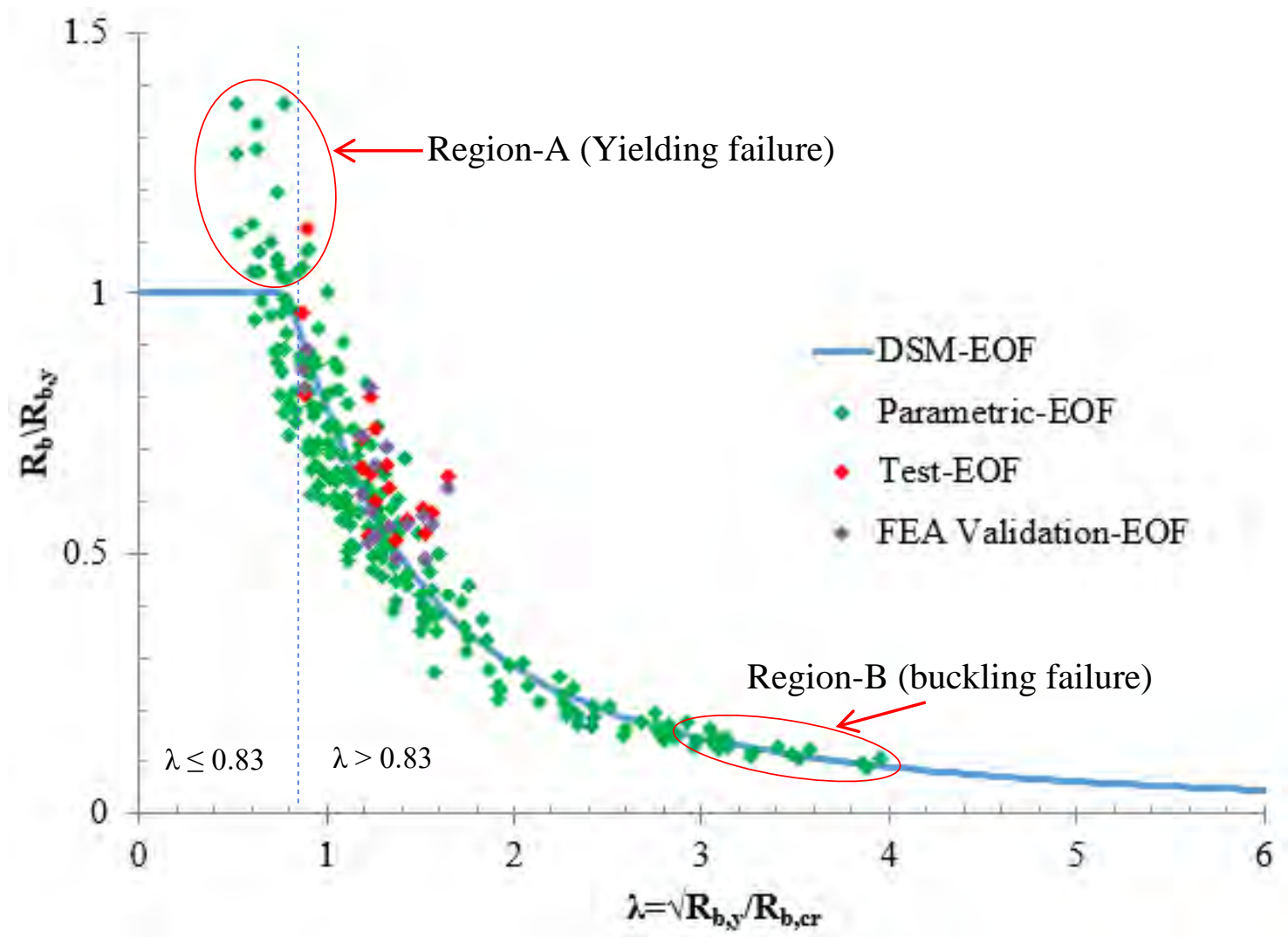

(a) EOF Load Case

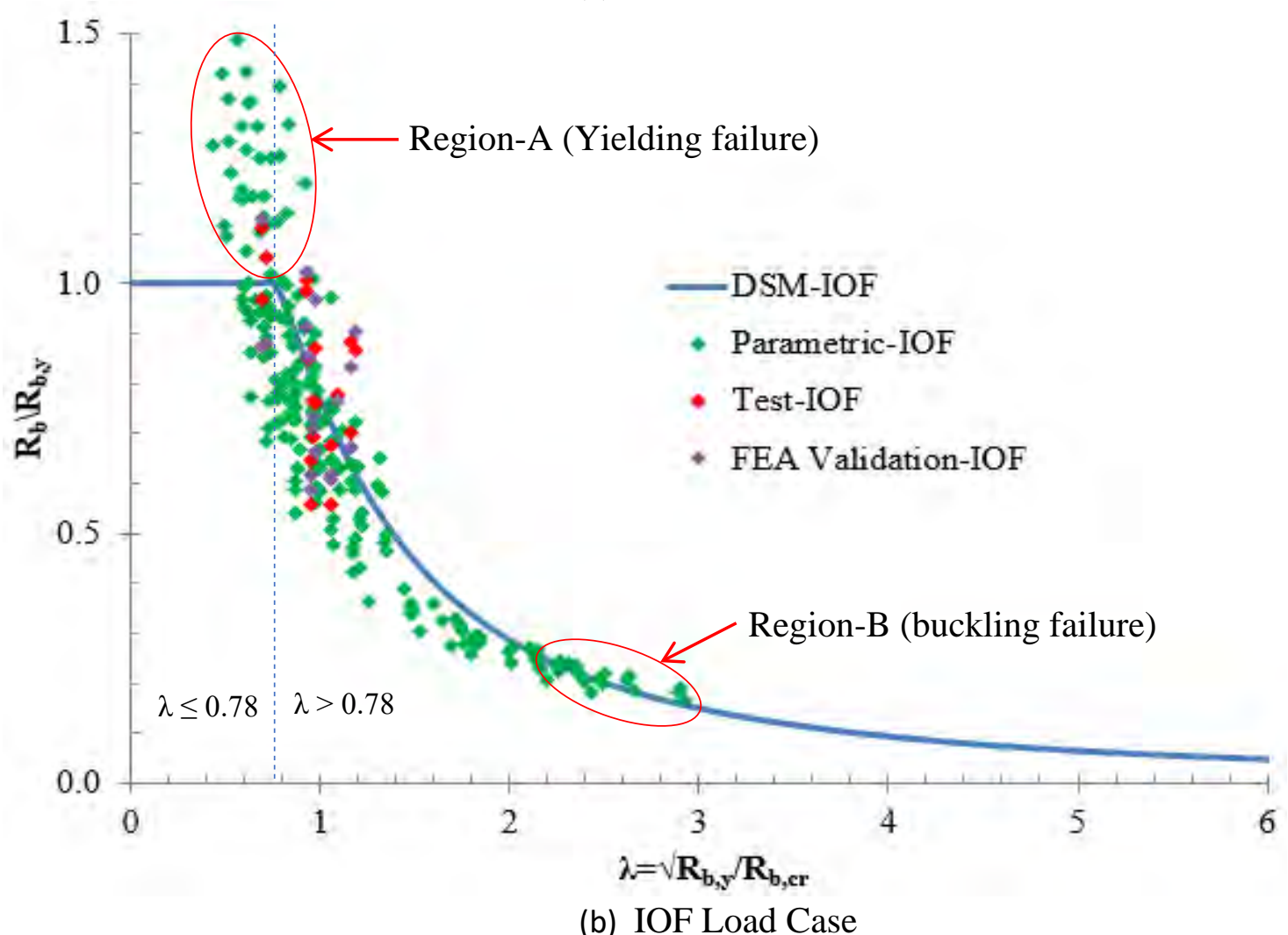

Fig. 17: Comparison of web crippling capacities of lipped channels from Test and parametric studies with DSM based Design Equation - one-flange load cases [21] 


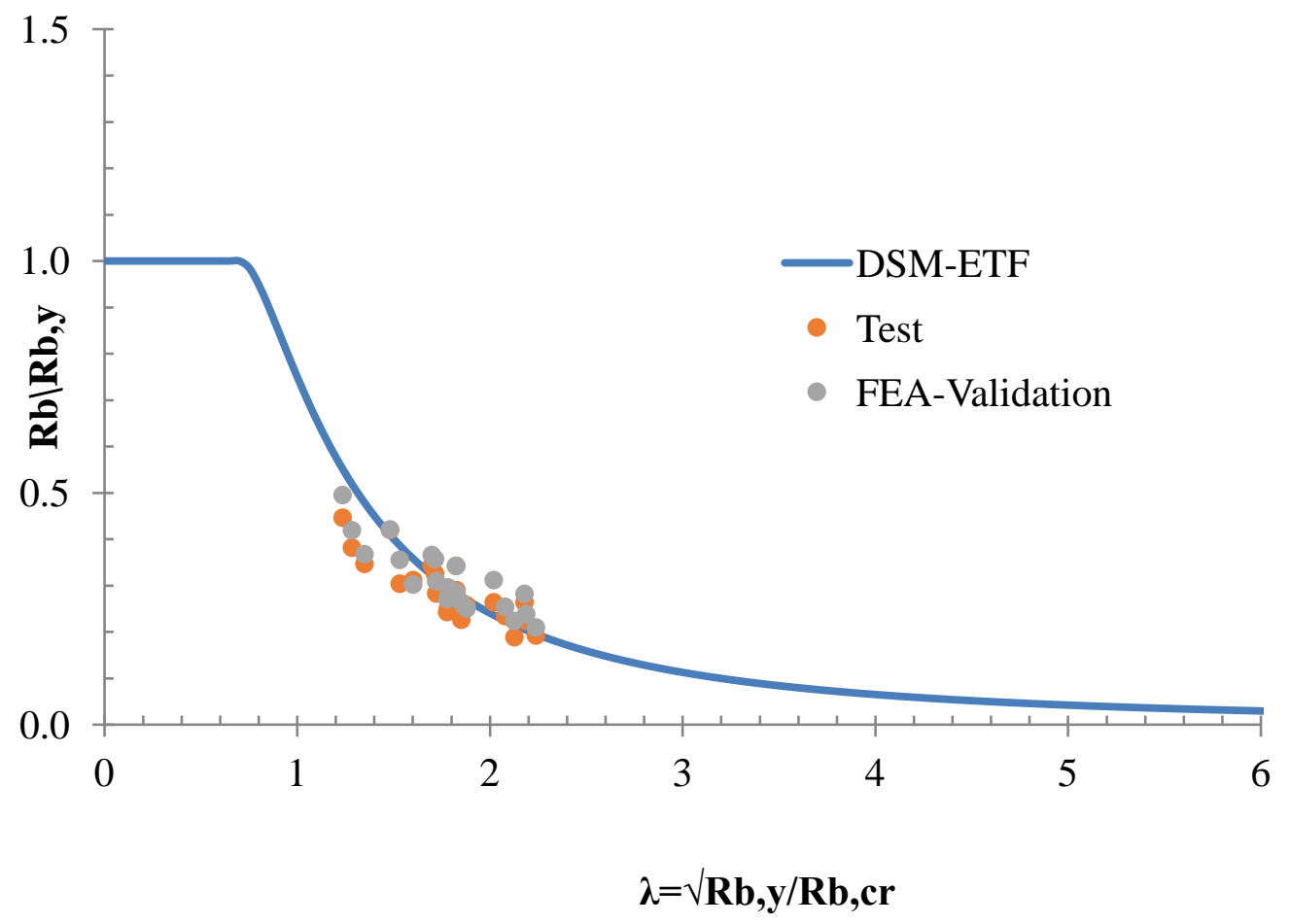

(a) ETF Load Case

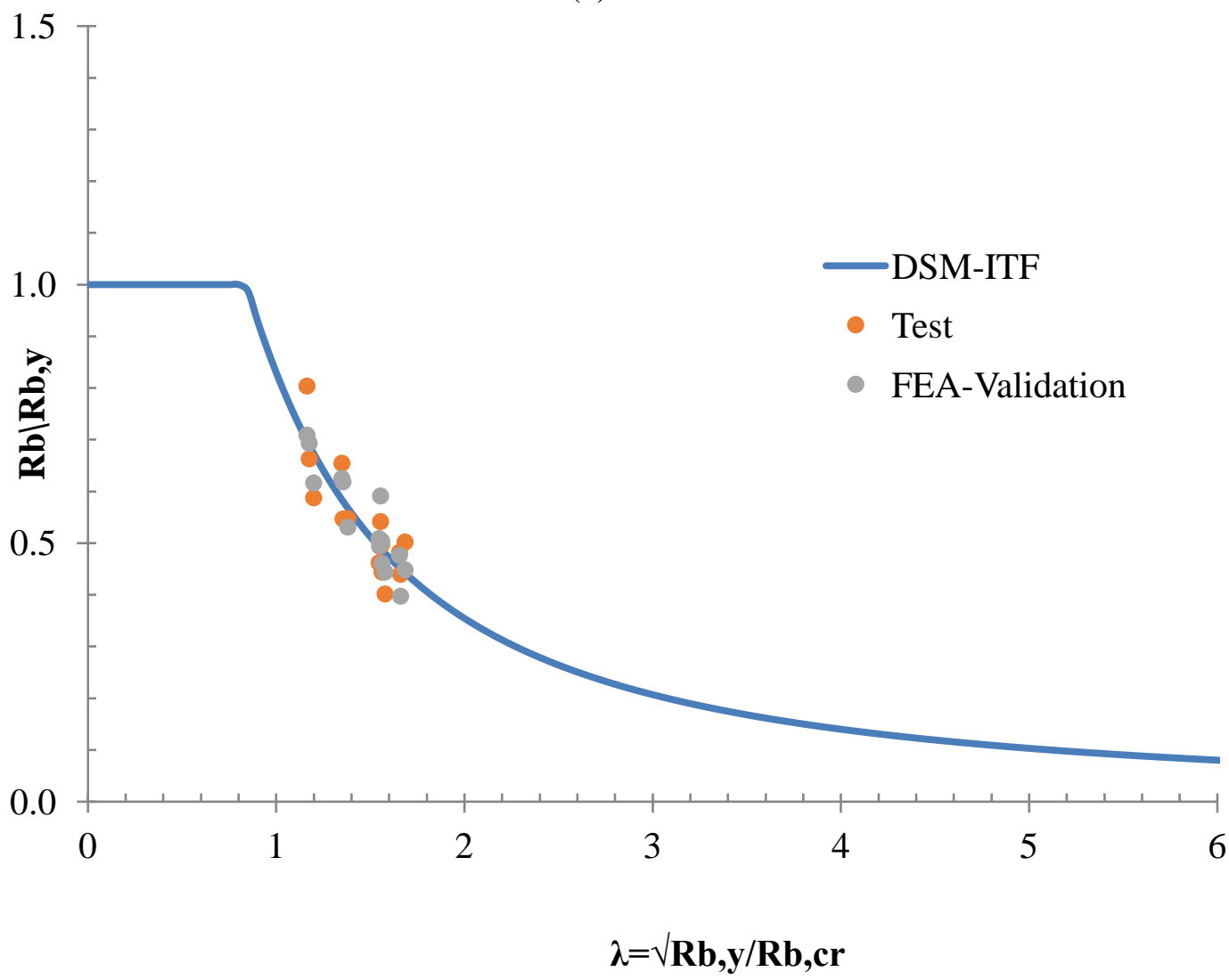

(b) ITF Load Case

Fig. 18: Comparison of web crippling capacities of SupaCee sections from Tests and FEA with DSM based Design Equation - two-flange load cases [21] 


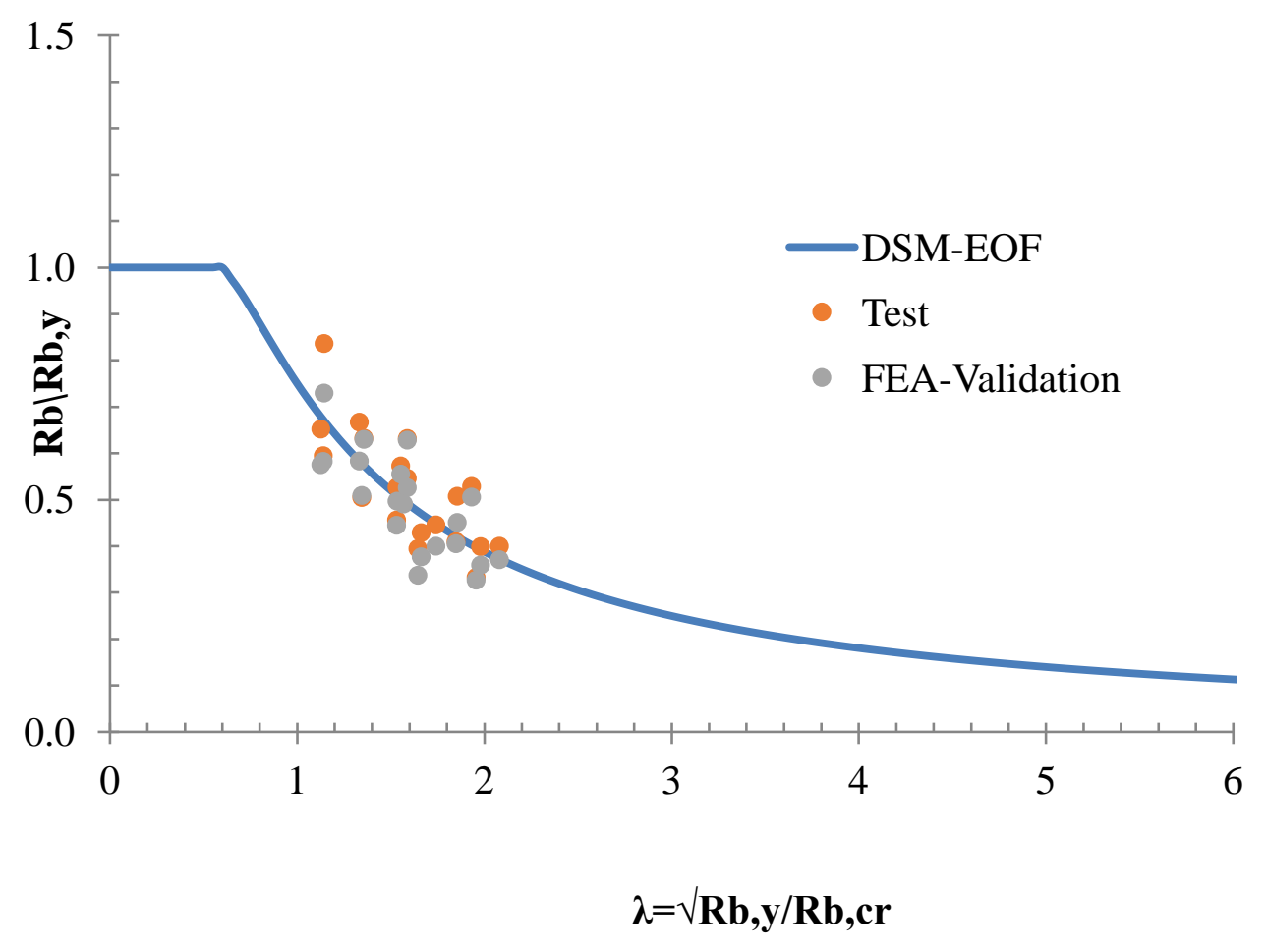

(a) EOF Load Case

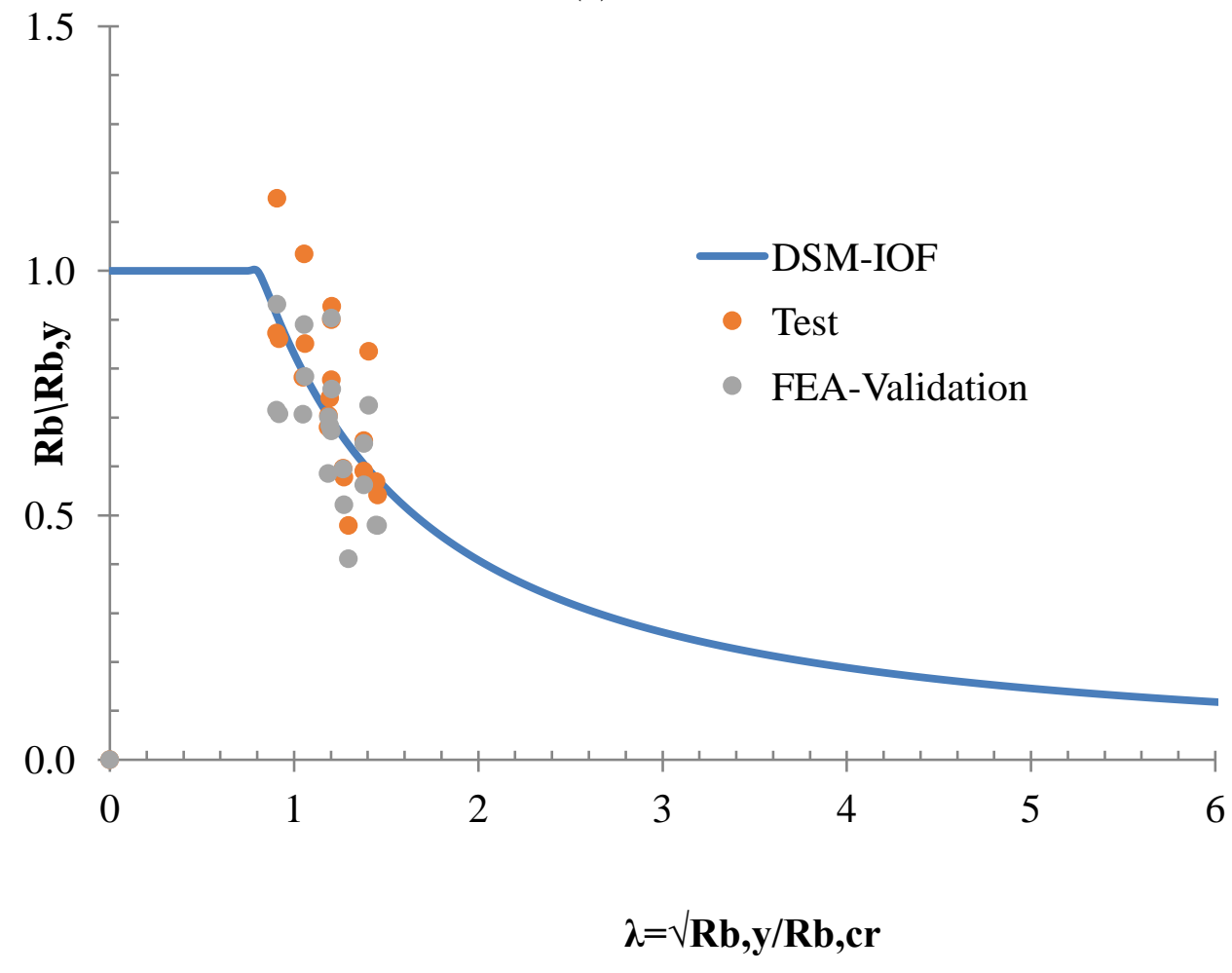

(b) IOF Load Case

Fig.19: Comparison of web crippling capacities of SupaCee sections from Tests and FEA with DSM based Design Equation - one-flange load cases [21] 